\title{
Chemical genetics approach to restoring p27Kip1 reveals novel compounds with antiproliferative activity in prostate cancer cells
}

\author{
Elizabeth Rico-Bautista ${ }^{1 *}$, Chih-Cheng Yang ${ }^{1}$, Lifang Lu ${ }^{1,2}$, Gregory P Roth ${ }^{3}$, Dieter A Wolf ${ }^{1 *}$
}

\begin{abstract}
Background: The cyclin-dependent kinase (CDK) inhibitor $p 27^{\text {Kip } 1}$ is downregulated in a majority of human cancers due to ectopic proteolysis by the ubiquitin-proteasome pathway. The expression of p27 is subject to multiple mechanisms of control involving several transcription factors, kinase pathways and at least three different ubiquitin ligases (SCF ${ }^{\text {SKP2 }}$, KPC, Pirh2), which regulate p27 transcription, translation, protein stability and subcellular localization. Using a chemical genetics approach, we have asked whether this control network can be modulated by small molecules such that p27 protein expression is restored in cancer cells.

Results: We developed a cell-based assay for measuring the levels of endogenous nuclear p27 in a high throughput screening format employing LNCaP prostate cancer cells engineered to overexpress SKP2. The assay platform was optimized to Z' factors of $0.48-0.6$ and piloted by screening a total of 7368 chemical compounds. During the course of this work, we discovered two small molecules of previously unknown biological activity, SMIP001 and SMIP004, which increase the nuclear level of p27 at low micromolar concentrations. SMIPs (small molecule inhibitors of p27 depletion) also upregulate p21 ${ }^{\mathrm{Cip} 1}$, inhibit cellular CDK2 activity, induce G1 delay, inhibit colony formation in soft agar and exhibit preferential cytotoxicity in LNCaP cells relative to normal human fibroblasts. Unlike SMIP001, SMIP004 was found to downregulate SKP2 and to stabilize p27, although neither SMIP is a proteasome inhibitor. Whereas the screening endpoint - nuclear p27 - was robustly modulated by the compounds, SMIP-mediated cell cycle arrest and apoptosis were not strictly dependent on p27 and p21 - a finding that is explained by parallel inhibitory effects of SMIPs on positive cell cycle regulators, including cyclins E and A, and CDK4.

Conclusions: Our data provide proof-of-principle that the screening platform we developed, using endogenous nuclear p27 as an endpoint, presents an effective means of identifying bioactive molecules with cancer selective antiproliferative activity. This approach, when applied to larger and more diverse sets of compounds with refined drug-like properties, bears the potential of revealing both unknown cellular pathways globally impinging on p27 and novel leads for chemotherapeutics targeting a prominent molecular defect of human cancers.
\end{abstract}

\section{Background}

p27 is a cyclin-dependent kinase (CDK) inhibitor (CKI) that controls cell proliferation, cell motility and apoptosis [1]. It regulates the progression of cells from $\mathrm{G} 1$ to $\mathrm{S}$ phase by binding and inhibiting the cyclin E-CDK2 complex. A plethora of evidence has implicated downregulation of p27 in prevalent human carcinomas [1]. For

\footnotetext{
* Correspondence: erico@sanfordburnham.org; dwolf@sanfordburnham.org 'Signal Transduction Program, Sanford-Burnham Medical Research Institute, La Jolla, CA 92037, USA

Full list of author information is available at the end of the article
}

example, downregulation of p27 is among the most frequent non-genetic molecular alterations in prostate cancer ( $\mathrm{PCa})$ [2]. In this disease, low p27 expression is correlated with a number of prognostic morphological features [3] and with decreased survival [4]. In contrast, ectopic expression of p27 can inhibit cell cycle progression in a human PCa cell line [5], suppress astrocytoma growth in nude mice [6] and induce the death of breast cancer cells [7]. Based on these findings, p27 has been denoted as a tumour suppressor.

\section{Biomed Central}


The regulation of p27 during the cell cycle is very complex [1]. It involves regulation at the level of transcription, messenger (m)RNA translation [8] and protein stability. The distribution among different cyclin-CDK complexes [9], its sub-cellular localization [10] as well as phosphorylation of several residues in p27 are important mechanisms of control [11-13]. p27 levels are high in quiescent cells and decrease rapidly upon mitogenic stimulation. However, the cell cycle-dependent variations in p27 levels are not reflected by similar changes in p27 mRNA $[8,14]$. Unlike traditional tumour suppressor genes, the p27 gene rarely undergoes homozygous inactivation in cancer cells [15-17], a finding that points towards alternative mechanisms of p27 inactivation. Many aggressive cancers display decreased p27 protein levels in the presence of high p27 mRNA $[18,19]$, suggesting that p27 depletion is primarily a result of ectopic proteolysis.

The p27 protein accumulates in cells when the ubiquitin proteasome system (UPS) is inhibited [20]. This system employs a cascade of enzymatic reactions that covalently attach a ubiquitin chain to a substrate protein [21], leading to the recognition by the proteasome for degradation. Biochemical studies identified $\mathrm{SCF}^{\mathrm{SKP} 2}$, an ubiquitin ligase complex that mediates phosphorylationdependent p27 ubiquitylation in vitro $[13,22]$. Two other enzymes, KPC and PIRH2, have been also been implicated as E3s for p27 [23-25]. Whereas SCF ${ }^{\text {SKP2 }}$ mediates the degradation of nuclear p27 throughout $\mathrm{S}$ phase and G2, KPC targets cytoplasmic p27 upon cell cycle entry from G0 [23,25]; PIRH2 instead targets nuclear and cytoplasmic p27 [24].

Considerable evidence suggests, however, that SKP2 is the prominent regulator of p27 levels in cancer cells [26]. SKP2 overexpression is frequent in human carcinomas devoid of p27 [27-32]. In addition, our own data have shown that SKP2 overexpression in LNCaP prostate cancer cells is sufficient to direct p27 ubiquitylation and degradation [33]. Furthermore, transgenic expression of SKP2 in the mouse prostate causes low-grade prostate carcinomas that coincide with p27 downregulation [32]. Conversely, RNA interference (RNAi)mediated knockdown of SKP2 expression inhibits tumour growth in a mouse transplant model [34]. These findings validated p27 degradation pathways as promising cancer drug targets [35].

The complexity of p27 regulation presents considerable challenges to drug development because of the potential for redundancies. Thus, it is not readily apparent which enzyme involved in p27 regulation should be targeted in order to effect sustained p27 accumulation in cancer cells. In addition, pharmacological agents active in an enzyme assay in vitro are not necessarily bioactive in intact cells. Rather than targeting a preselected component, we have developed a method for the up-front identification of compounds that are bioactive in restoring physiological levels of p27 in prostate cancer cells. Using a validated cell-based assay, two compounds, small molecule inhibitors of p27 depletions (SMIPs) 001 and 004, were identified, which had the desired activity. SMIPs restored p27 to physiological levels, inhibited CDK2 activity and caused cell cycle delay or apoptosis selectively in prostate cancer cells but not normal cells.

\section{Results}

Generation and validation of an LNCaP-derived screening cell line overexpressing SKP2

Prostate cancers typically display an inverse correlation between the levels of p27 and SKP2 [29]. In contrast, the commonly used human prostate cancer cell line LNCaP, despite faithfully recapitulating many features of human prostate cancer [36], expresses relatively high levels of p27 but low levels of SKP2 when compared to HeLa cells (Figure 1a). In order to mimic the situation prevailing in primary prostate cancers, we created the LNCaP derivative cell line, LNCaP-S14, which stably overexpresses Myc-tagged SKP2 at six to eightfold excess over endogenous SKP2, a manoeuvre that led to maximal downregulation of p27 (Figure 1b). The same pattern was apparent by immunofluorescence staining; while nuclear levels of p27 are low in LNCaP-S14 cells, nuclear SKP2 levels are highly elevated (Figure 1c).

We also determined whether known inhibitors of p27 degradation could upregulate p27 in LNCaP-S14 cells. Upon normalization to the loading control actin, the proteasome inhibitors MG132, epoxomycin and bortezomib caused between 1.2 and 1.7 -fold upregulation of p27, while the CDK inhibitor roscovitine led to 1.5 -fold accumulation (Figure 1d). The induction of nuclear p27 by MG132 and roscovitine was also apparent by immunofluorescence (Figure 1e).

\section{Development of a high throughput screening assay to score the level of nuclear p27}

The immunofluorescence assay used in Figure 1c and 1e was adapted to 384 well plate format. All parameters, including the number of cells to be seeded, fixation, blocking conditions, antibody concentrations and incubation times with compounds were extensively optimized using positive (proteasome and CDK inhibitors) and negative (dimethyl sulfoxide; DMSO) controls, resulting in the reliable protocol described in the Methods section. Representative images of LNCaP-S14 cells treated with DMSO or roscovitine and stained with the above protocol in 384 well plates are shown in Figure 1f.

In order to evaluate the performance of our assay to reliably measure the percentage of p27 positive cells in a cell 


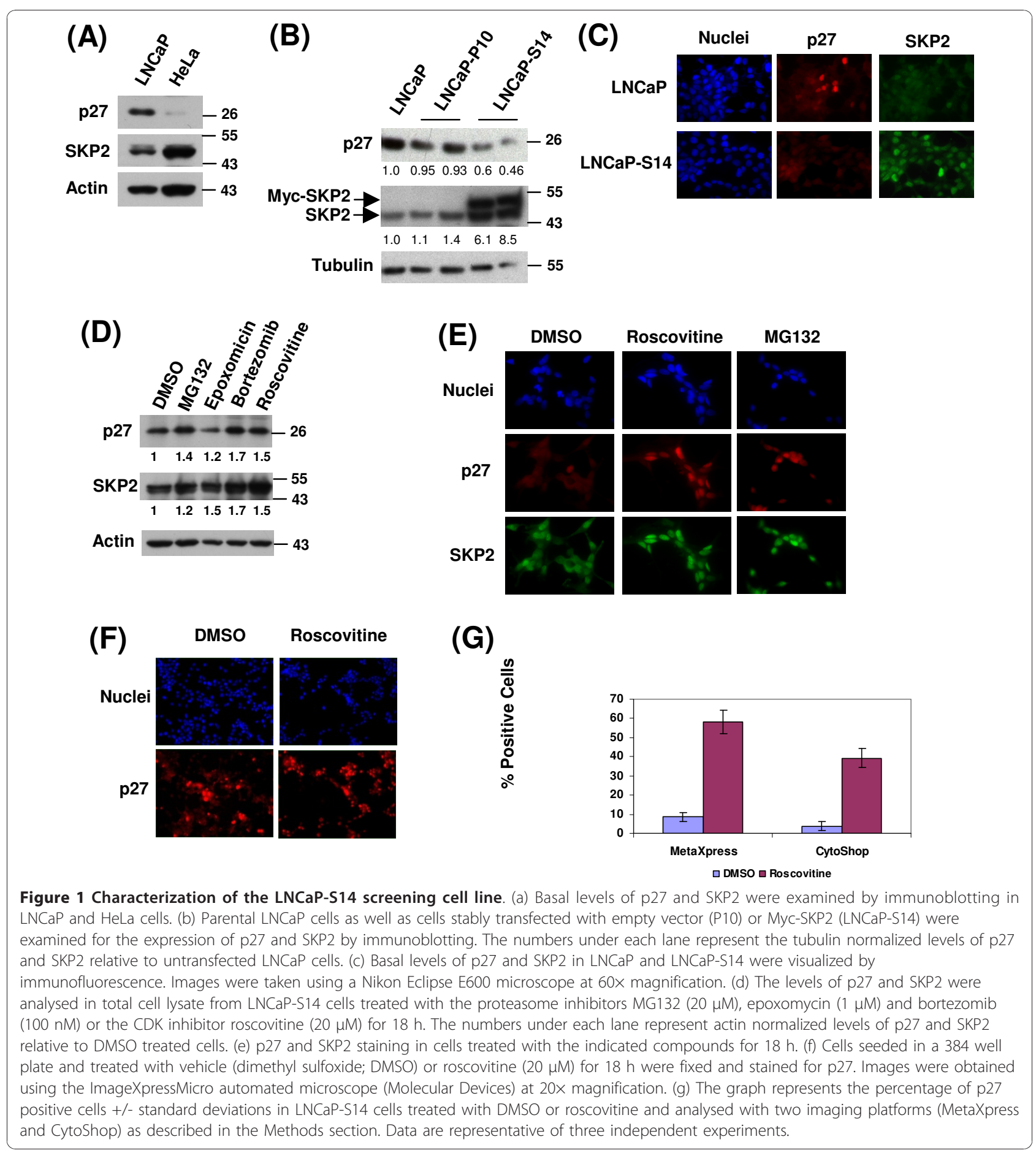

population, we determined the Z'-factor for the positive control reagent roscovitine. The Z'-factor measures the variation and separation bands of an assay thereby providing a statistical measure of its quality. It takes into account the dynamic range and variability of the positive and negative control measurements [37]. We determined a Z'-factor of 0.48 using the ImageXpress Micro and MetaXpress software from Molecular Devices (CA, USA) and 0.60 using the Cell Lab IC100 and Cytoshop software from Beckman Coulter (USA). Both values are deemed appropriate for a successful screen [37]. Figure 1g shows the signal-to-background ratios using both imaging platforms.

\section{Primary screen}

In order to assess the utility of the above protocol, we performed a pilot screen of 7368 compounds (derived 
from a variety of different compound libraries, see Methods) in duplicates for a total of 44.384-well plates. LNCaP-S14 cells were incubated with individual compounds (final concentration varied between $\sim 5$ and $35 \mathrm{uM}$ depending on the molecular weights of the compounds) for $18 \mathrm{~h}$, followed by fixation, staining, imaging (automatic microscopy) and analysis as described in Methods. We scored the percentage of cells positive for p27 in each well relative to the vehicle control (DMSO). Figure 2a shows the activity of positive control compounds (yellow triangles), the negative control compound DMSO (red squares), the non-specific staining (blue diamonds) and small molecules derived from compound libraries (blue circles) across all screening plates
(44 plates) prior to normalization. Negative controls (DMSO) gave basal percentages of p27 positive cells ranging between $2 \%$ and $13 \%$ while the positive control roscovitine increased these populations up to $50 \%$. As expected, the average of $\sim 320$ well measurements per plate - that is, the percentage of p27 positive cells in wells treated with individual compounds - was similar to the percentage of $\mathrm{p} 27$ positive cells in the negative control (DMSO), indicating that most compounds tested were inactive in causing p27 accumulation (Figure 2a).

Normalization of raw data for 7368 compounds was performed by calculating $\mathrm{Z}$ scores, which represent the number of standard deviations by which a signal for a given compound differed from the mean signal of the

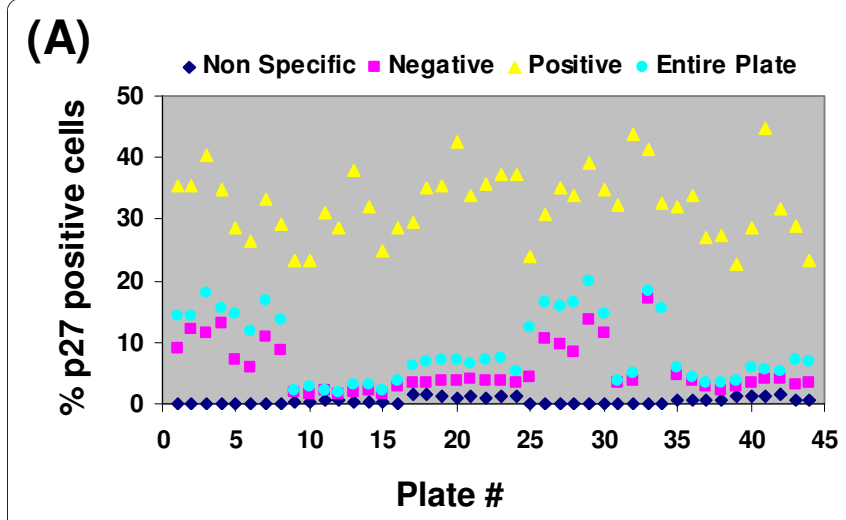

(B)
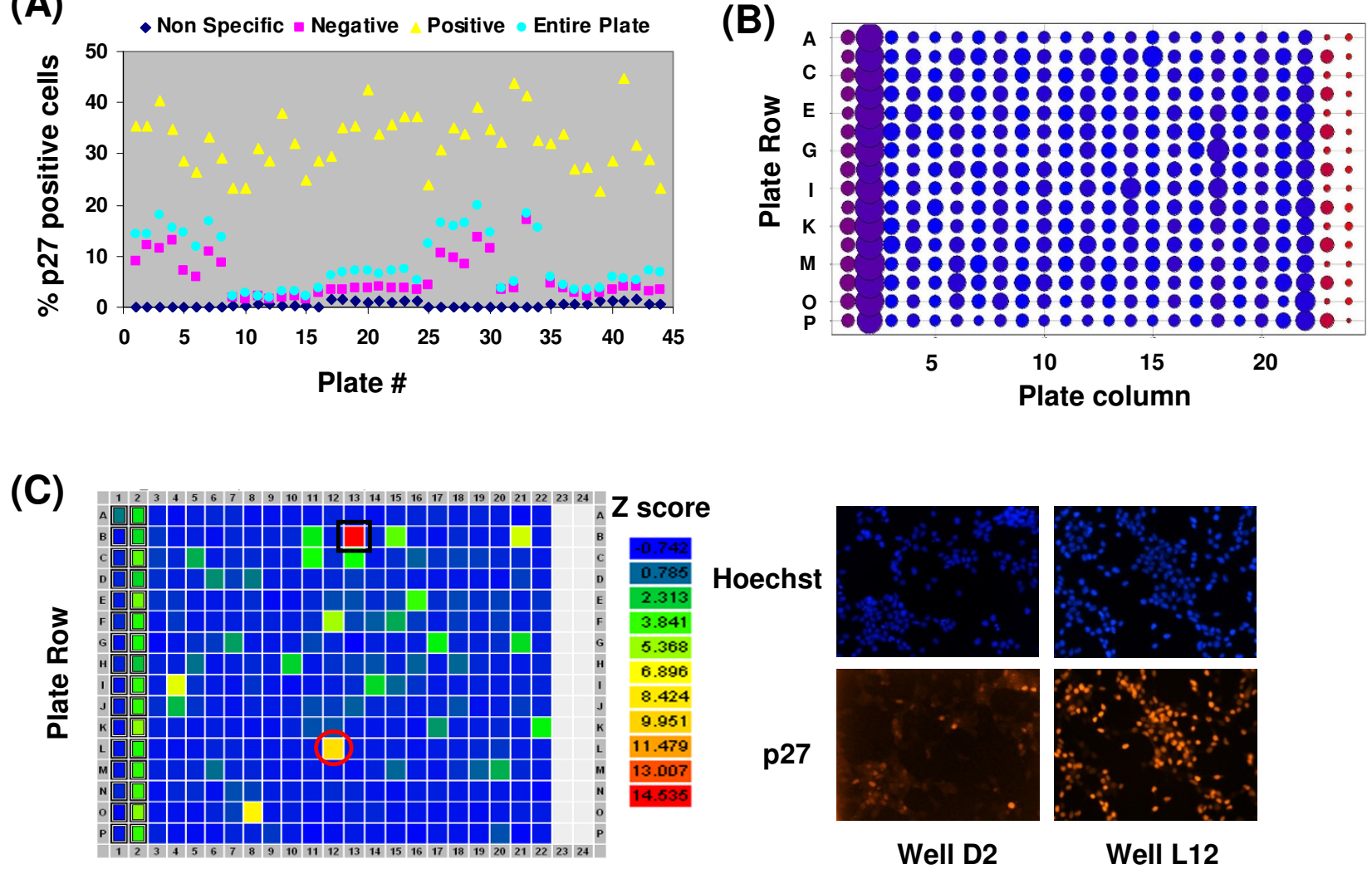

\section{Plate Column}

Figure 2 Assay data from the primary screen. (a) The graph represents the mean percentages of p27 positive cells detected across all wells in each of the 44 screening plates (blue circles). The data are further stratified by treatment: Red squares indicate the mean percentages obtained with the negative control (dimethyl sulfoxide; DMSO), yellow triangles indicate the mean percentages obtained with the positive control (roscovitine). Blue diamonds indicate the mean percentages obtained by staining without the primary p27 antibody (non-specific background staining). (b) Sum Z-scores. The heat map represents the sum of Z-scores from each well in 22 plates. DMSO (negative control) was added to column 1, roscovitine (positive control) to column 2, and in some cases to columns 22 and 23, and the non-specific staining was performed in columns 23 and 24. (c) Heat map of a representative screening plate showing potential hits based on their Z score. The first column on the plate contained the negative control DMSO, the second column contained the positive control agent roscovitine, and columns 23 and 24 were stained without the primary p27 antibody (non-specific background staining). The well marked with a black square was identified as containing a false positive compound, whereas the red circle indicates a potential hit. A representative micrograph from well L12 (potential hit) is shown to the right. 
entire plate [38]. It excludes control measurements altogether under the assumption that most compounds are inactive and can serve as intrinsic controls. The summed Z scores for one set of duplicates (22 plates) showed clear separation between the positive control compound roscovitine (column 2) and the non-specific staining (cells treated with DMSO or stained with secondary antibody only, columns 23 and 24; Figure 2b). In addition, most summed $\mathrm{Z}$ scores had values similar to the negative controls (DMSO), indicating that we did not incur errors caused by plate position of compounds. This was further evaluated by visualizing every plate as a heat map of individual $\mathrm{Z}$ scores. As shown in the example of a single plate in Figure 2c, potential hits were randomly distributed over the plate (green and yellow positions). The analysis also identified several falsepositive compounds with very high $\mathrm{Z}$ scores, namely known DNA binding compounds of red colour (doxorubicin and derivatives, crystal violet, homidium bromide, propidium iodine, pararosalinine pamoate).

\section{Results of the primary screen}

In the initial primary screen, we identified 249 compounds that increased the percentage of p27 positive LNCaP-S14 cells. Upon manual examination of microscopic images, 21 duplicate compounds (occurring in more than one library), seven obvious false positives (DNA stains) and 45 compounds with low quality staining (few cells left in well, background, indiscriminate whole cell staining) were sorted out. This resulted in a list of 176 candidates (Additional File 1, Supplementary Table 1 ) with sixty compounds classified as strong ( $Z$ score $>5$ ), 58 as medium ( $Z$ score $3-5$ ) and the remainder as weak ( $Z$ score 2-3; Figure $3 a$ ). At a $Z$ score of 3 , a compound has a theoretical probability of 0.0013 of being a false positive hit.

A number of experimental and clinically used chemotherapeutics such as camptothecin, thapsigargin, 17$\mathrm{N}$-allylamino-17-demethoxygeldanamycin, mitomycin $\mathrm{C}$ and etoposide were identified (Additional File 1, Supplementary Table 1). The PI3 kinase inhibitor Wortmannin also scored positive, a finding that is consistent with the known role of the PI3K/AKT pathway in the downregulation of p27 through SKP2 [39]. We further validated some of the known bioactive compounds by immunofluorescence staining and immunoblotting (Figure $3 \mathrm{~b}$ and 3c; data not shown).

\section{Secondary screening}

The one hundred and nine most potent compounds $(Z \geq 3)$ were selected for confirmation by secondary screening using the primary screening assay. After statistical analysis, 60 compounds were still considered positive hits (Figure 3d). It is well established that
Table 1 Cytotoxicity was analysed by MTT assay in LNCaP-S14 and IMR90 cells treated with increasing concentrations $(0.01-40 \mu \mathrm{M})$ of the respective small molecule inhibitors of p27 depletion (SMIPs) for $\mathbf{7 2 ~ h}$

\begin{tabular}{ccc}
\hline & LNCaP-S14 & IMR90 \\
\hline MG132 & 0.379 & 0.445 \\
Thapsigargin & 0.0078 & 0.031 \\
SMIP001 & $\mathbf{4 . 6 3}$ & $>\mathbf{2 0}$ \\
SMIP002 & 11.09 & $>40$ \\
SMIP003 & 15.92 & 65.36 \\
SMIP004 & $\mathbf{1 . 0 9}$ & $>\mathbf{2 0}$ \\
SMIP005 & 1.71 & 17.38 \\
SMIP006 & 6.63 & NT \\
SMIP009 & $>40$ & $>40$ \\
SMIP011 & $>40$ & $\sim 40$ \\
SMIP012 & 4.59 & $\sim 10$ \\
SMIP013 & 18.15 & $\sim 20$ \\
SMIP015 & 13.02 & $\sim 20$ \\
SMIP016 & 14.63 & 4.41 \\
SMIP017 & 23.73 & $>40$ \\
SMIP018 & $>40$ & $>40$ \\
SMIP019 & NT & $\sim 40$
\end{tabular}

NT: not tested.

The data in the table represents the IC50 $(\mu \mathrm{M})$.

compounds with high activity in the primary screen will appear less potent in the secondary screen because of a statistical effect known as 'regression towards the mean' [38]. Thus, weaker hits often fail to validate in the secondary screen due to random measurement error. Additional counter screening for autofluorescence identified another false-positive (pyrvinium pamoate).

Thirty-seven of the 60 validated compounds had known biological activity (for example, inhibitors of protein synthesis and topoisomerase activity, antibiotics and antihelmintics). Of the remaining 23 compounds, none of which had known bioactivity, 20 were prioritized for further characterization based on features of their chemical structures. These compounds were denoted small molecule inhibitors of p27 depletion, SMIPs.

\section{Activity and specificity of SMIPs in p27 accumulation}

Sixteen of the 20 SMIPs were obtainable as powders from commercial sources. The identity and integrity of all compounds was confirmed by high-performance liquid chromatography (HPLC) and mass spectrometry (data not shown). SMIPs were retested for activity in a dose-response experiment using the primary screening assay. Thirteen out of 16 purchased SMIPs induced $\mathrm{a} \geq$ twofold increase in the percentage of p27 positive cells at the maximal dose with the remaining compounds having lower activity (data not shown). SMIP014 was identified as an additional false positive at this step (data not shown). 


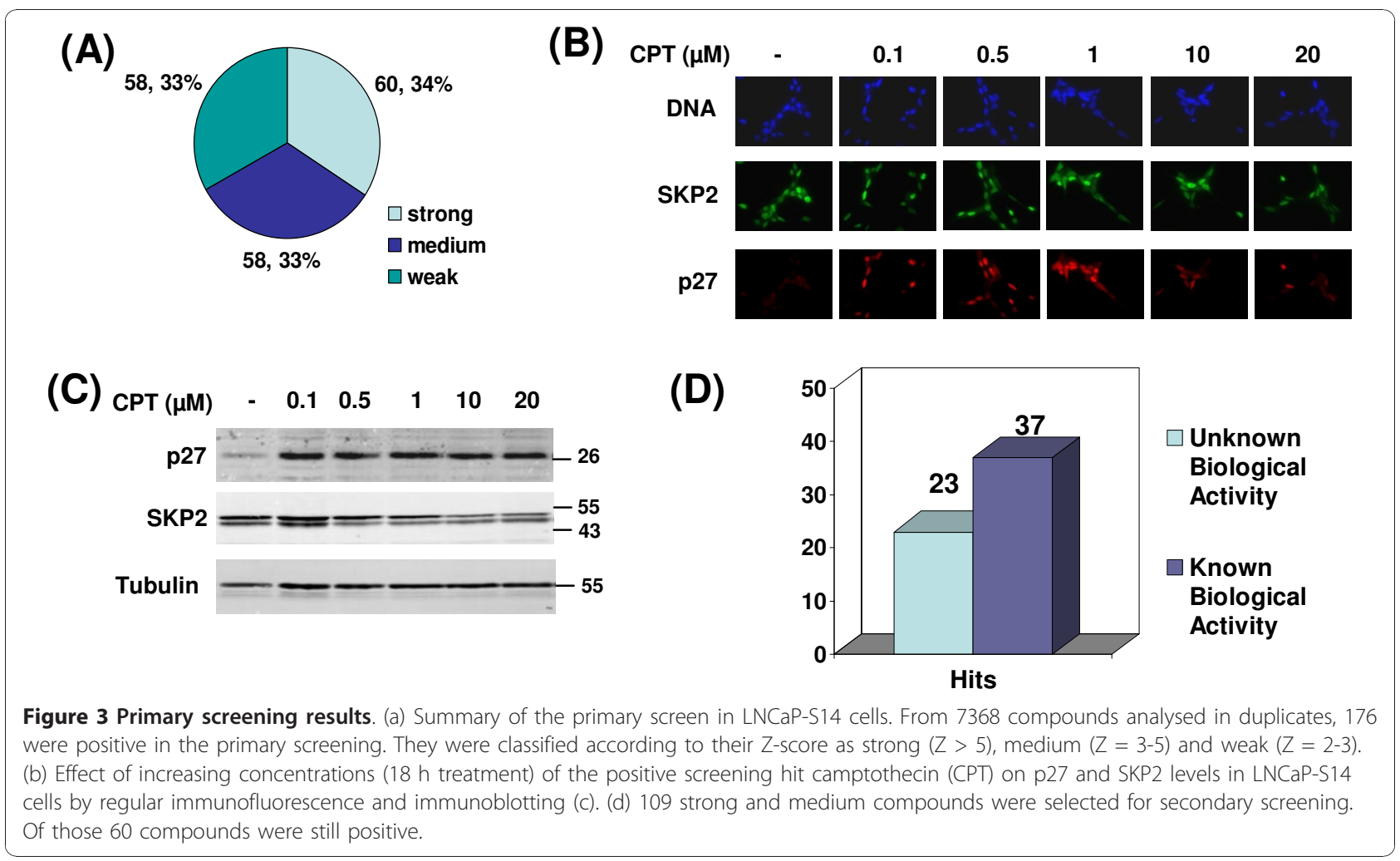

Several SMIPs also induced p27 accumulation as determined by immunoblotting (Figure 4a and 4b), although the effects were generally weaker ( twofold at $40 \mu \mathrm{M})$. While seemingly small, such an increase is biologically significant because p27 levels do not vary more than two- to threefold during a normal cell cycle ([40] and our own unpublished observation). This apparent discrepancy between the immunofluorescence and immunoblotting data, which we had encountered previously during assay development (with positive control compounds roscovitine and MG132; Figure 1c and data not shown), is explained by the different metrics of the assays: While the immunofluorescence assay determines the percentage of cells with nuclear p27 staining above a threshold determined by staining with secondary antibody alone, the immunoblotting assay measures the total amount of p27 that can be extracted from a cell population (no threshold).

Further prioritization of the remaining 15 SMIPs was achieved by counter screening against another unstable prostate tumour suppressor (NKX3.1) [41,42]. In order to address target specificity, LNCaP cells stably overexpressing NKX3.1 fused to yellow fluorescent protein (NKX3.1-YFP) were used. Cells were treated with a single concentration $(40 \mu \mathrm{M})$ of SMIPs in 384-well plates and analysed by automated microscopy (see the Methods section). The Z' factors for this assay, as determined by positive and negative controls, were between 0.62 (epoxomycin) and 0.67 (MG132), while the signal-tobackground ratio was five in both cases. Although some SMIPs $(005,006,016)$ caused a $\sim$ twofold increase in the percentage of NKX3.1 positive cells, the effect was subtle in comparison to proteasome inhibitors ( fivefold; Figure 4c) and could not be confirmed by immunoblotting (data not shown). Likewise, when the expression of endogenous NKX3.1 was evaluated in DU145, another prostate cancer cell line with very low levels of NKX3.1, none of the SMIPs scored positive (data not shown). The minor effects of some SMIPs in the NKX3.1-YFP fluorescence assay were most likely an artifact of compound autofluorescence at the wavelength used to excite YFP.

We also determined the effect of SMIPs on a HeLa cell line stably expressing p27 fused to firefly luciferase (p27-luc) [40,43]. While proteasome inhibitors led to an increase in p27-luc expression, which was readily apparent by luciferase assay (Figure 4d) and immunoblotting (data not shown), none of the SMIPs were active. This finding suggests a certain degree of cell type specificity of SMIP action.

SMIPs inhibit cell growth and induce cell death Since p27 can drive cell cycle arrest, senescence, and apoptosis $[7,44,45]$, we assessed the effect of SMIPs on 


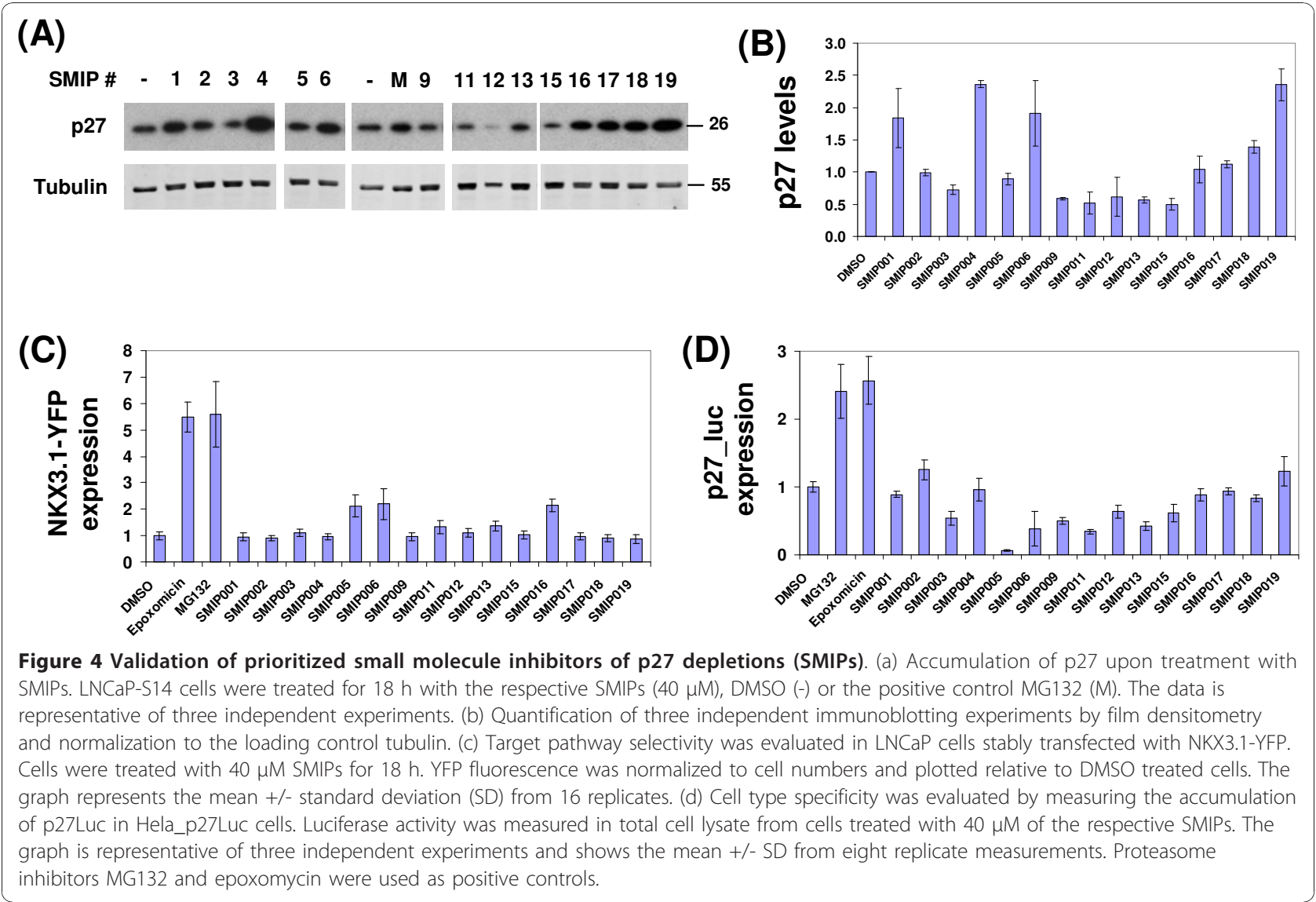

cell proliferation and viability. LNCaP-S14 cells and IMR90 normal human fibroblasts were exposed to increasing concentrations of SMIPs for $72 \mathrm{~h}$ and scored using the MTT assay followed by calculation of $\mathrm{IC}_{50}$ values (concentration required for $50 \%$ inhibition) (Table 1). Whereas SMIP012 and 016 were moderately toxic in normal fibroblasts, SMIPs 001 and 004 showed substantial cancer cell specificity being at least five times more potent in LNCaP-S14 than in IMR90 cells. Although SMIP005 also showed good cell type selectivity, it was excluded at this point due to structural features that suggested potential unspecific reactivity with cellular macromolecules. Based on their apparent cancer cell specificity and their chemical structures, SMIPs 001 and 004 were selected for additional studies.

\section{SMIPs induce dose-dependent accumulation of p27 and p21}

Figure 5a shows the chemical structures of the two compounds. We next confirmed the accumulation of p27 upon treatment with $40 \mu \mathrm{M}$ SMIP001 and 004 in LNCaP-S14 cells (Figure 5b). The CKI p21, which was described as another ubiquitylation target of SKP2 [46], was also upregulated by SMIPs (Figure 5b). The effects on p27 and p21 were also observed with the CDK inhibitor roscovitine. Interestingly, SMIP004 caused a decrease in the levels of both the endogenous and the exogenous, stably expressed SKP2. In contrast, treatment of normal human fibroblasts with SMIPs did not affect p27 or p21 levels (see below).

In order to evaluate the dose-response of the effect on p27, LNCaP-S14 cells were treated with increasing concentrations of the respective SMIPs $(5-40 \mu \mathrm{M})$, and the percentage of cells with nuclear p27 was measured by immunofluorescence and automated microscopy. Both SMIPs led to a dose-dependent increase in p27 positive cells (Figure 5c). Dose-dependent increases in p27 and p21 were also observed by immunoblotting (Figure 5d). Whereas SMIPs 004 led to $\sim$ threefold induction at $40 \mu \mathrm{M}$, SMIP001 was less active in this experiment causing only a modest accumulation of p27 (30\%-40\%).

In order to begin to determine the mode of action of SMIPs, we measured their effects on p27 protein stability in a cycloheximide chase experiment. Whereas the half-life of p27 was $\sim 1.29 \mathrm{~h}$ in cells treated with DMSO, a value that is in good agreement with published reports (for example, [47]), treatment with either 


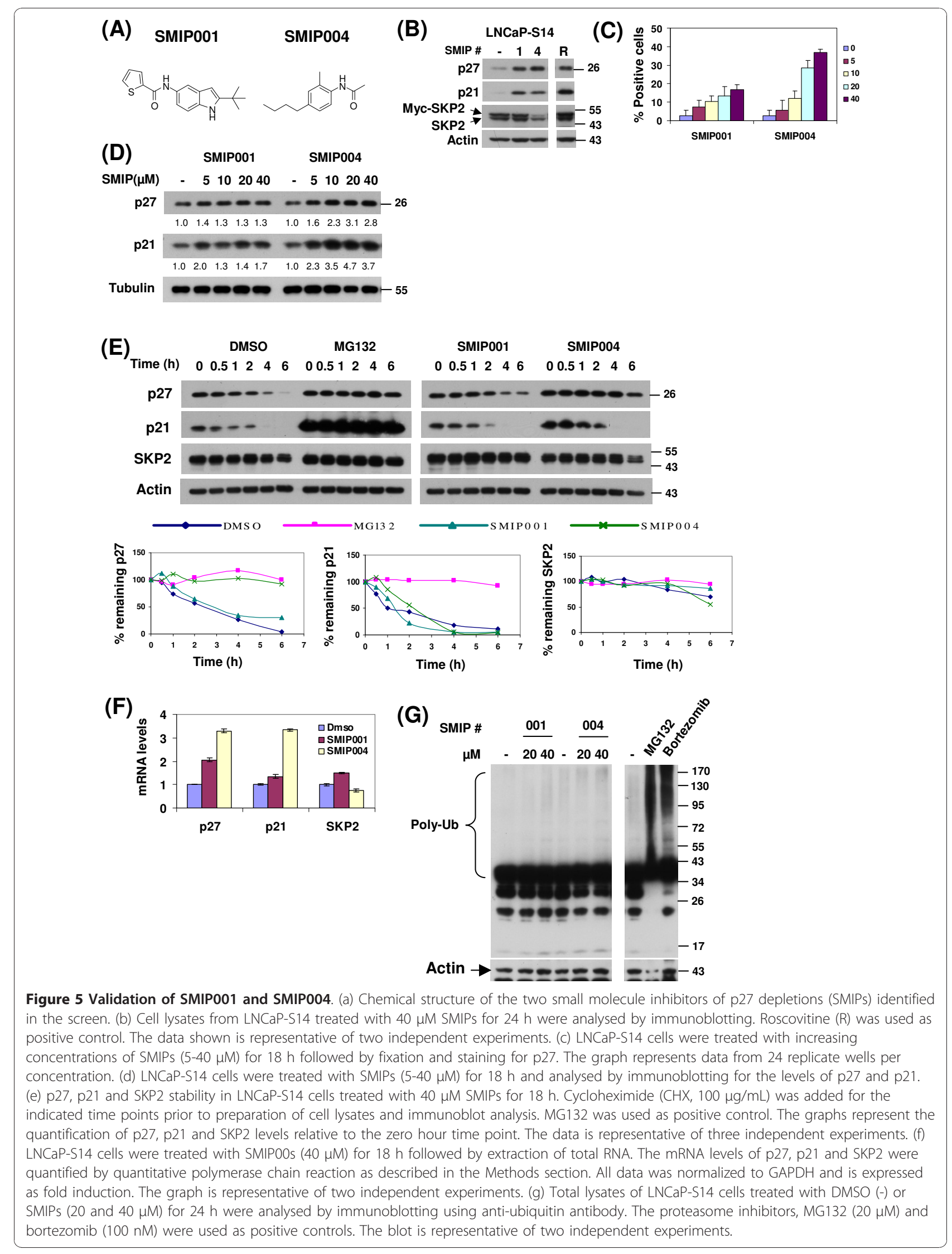


MG132 or SMIP004 increased p27 half-life to > $6 \mathrm{~h}$ (Figure 5f). No effect on p27 stability was seen for SMIP001. We also evaluated the stability of p21 and SKP2 but did not see any effects of SMIPs on these proteins. In summary, these data revealed a striking correlation between the ability of SMIP004 to downregulate SKP2 and to induce p27 stabilization. In contrast, SMIP001 appears to regulate p27 and p21 primarily at the level of mRNA expression (Figure $5 \mathrm{f}$ ).

Since SMIP004 replicated the effect of MG132 on p27, we tested whether it acts as a proteasome inhibitor. Total cell lysate from LNCaP-S14 cells treated with 20 and $40 \mu \mathrm{M}$ of the SMIPs were analysed by immunoblotting with anti-ubiquitin antibody to assess the abundance of polyubiquitylated proteins. None of the compounds caused the accumulation of polyubiquitylated proteins that was readily seen with the proteasome inhibitors MG132 and bortezomib (Figure 5g). Likewise, none of the SMIPs inhibited the proteolytic activity of purified $26 \mathrm{~S}$ proteasomes toward fluorogenic peptide substrates even when assayed at $40 \mu \mathrm{M}$ concentration (data not shown).

SMIPs cause inhibition of cellular CDK2 activity, G1 delay and apoptosis in LNCaP-S14 cells

Since SMIPs robustly upregulated p27 and p21, we asked whether this resulted in G1 delay. Indeed, SMIPs 001 and 004 induced a G1 delay with a concomitant decrease in the $S$ phase population (Table 2). We next asked whether the cell cycle delay coincided with inhibition of CDK2, one of the major cellular target kinases of p27 and p21. CDK2-cyclin complexes were immunoprecipitated from lysate of LNCaP-S14 cells treated with DMSO, the CDK inhibitor roscovitine or SMIPs and assayed for activity toward histone $\mathrm{H} 1$ in vitro. As with roscovitine, application of SMIPs led to strong inhibition of the CDK2 activity retrieved from cells (Figure 6a). In order to test the possibility that SMIPs act like roscovitine as direct inhibitors of CDK2 kinase activity, SMIPs were added to CDK2 complexes purified from untreated cells. Unlike roscovitine, none of the SMIPs inhibited CDK2 activity when added to the kinase reaction in vitro (Figure 6b), indicating that the two SMIPs are not kinase inhibitors.

We also evaluated the effect of SMIPs on the levels of p27, p21 and cyclins E and A complexed with CDK2 by coimmunoprecipitation. Both SMIP001 and 004 led to a strong increase in the recruitment of p27 to CDK2, while SMIP001 also slightly increased coprecipitation of p21 (Figure 6c). SMIP004 also reduced the amounts of cyclins E and A retrieved with CDK2 (Figure 6c). This was paralleled by a marked downregulation of cyclins $\mathrm{E}$ and A upon SMIP004 treatment (Figure 6c). A more variable downregulation of cyclin A and CDK4 was observed with SMIP001 (Figure 6e). Taken together, these findings suggested that SMIP-induced inhibition of CDK2 activity might be a combined consequence of p27/p21 upregulation and cyclin E/A downregulation.

In order to determine the specific contribution of $\mathrm{p} 27$ and p21 to SMIP-induced cell cycle delay, we performed siRNA-mediated knockdown studies. The depletion of p21 and p27 led to a decrease in the G1 population of untreated cells by 6 - 13 percentage points (Additional File 2), a finding that indicates biologically significant effects at the knockdown efficiencies achieved ( 80\%, Figure 6e). Surprisingly, however, neither individual nor combined knockdown of the two CKIs was able to abrogate SMIP-induced cell cycle delay (Figure 6d and Additional File 2). Likewise, CDK2 activity in SMIP-treated cells was not rescued by knockdown of p27 and p21 (data not shown). Finally, neither the downregulation of cyclins $\mathrm{E}$ and A nor that of CDK4 was consistently affected by knocking down the CKIs, suggesting that these effects of SMIPs probably account primarily for their G1 delay activity.

In addition to $\mathrm{G} 1$ delay, treatment of LNCaP-S14 cells with SMIPs for $24 \mathrm{~h}$ caused apoptosis as determined by the cleavage of poly-ADP ribose polymerase (PARP, Figure $6 \mathrm{f}$ and $6 \mathrm{~g})$. The apoptotic effect of SMIPs was independently evaluated by measuring the amount of

Table 2 Cell cycle distribution in protein prostate cancer cell lines treated with $40 \mu \mathrm{M}$ small molecule inhibitors of p27 depletion (SMIPs) for 24 and $48 \mathrm{~h}$

\begin{tabular}{|c|c|c|c|c|c|c|c|c|c|c|c|c|c|c|c|c|}
\hline \multirow[b]{2}{*}{ Time } & \multirow[b]{2}{*}{ SMIP } & \multicolumn{3}{|c|}{ LNCaP } & \multicolumn{3}{|c|}{$\begin{array}{c}\text { LNCaP } \\
\text {-S14 }\end{array}$} & \multicolumn{3}{|c|}{ DU145 } & \multicolumn{3}{|c|}{ PC3 } & \multicolumn{3}{|c|}{ IMR90 } \\
\hline & & G1 & $S$ & G2 & G1 & $S$ & G2 & G1 & $S$ & G2 & G1 & $\mathrm{S}$ & G2 & G1 & $\mathrm{S}$ & G2 \\
\hline \multirow[t]{3}{*}{$24 \mathrm{~h}$} & DMSO & 70.8 & 18.0 & 10.9 & 64.8 & 23.3 & 10.6 & 40.5 & 44.0 & 15.3 & 42.2 & 26.7 & 30.0 & 67.2 & 16.6 & 16.2 \\
\hline & SMIP001 & 84.5 & 6.6 & 7.6 & 84.8 & 7.2 & 6.3 & 65.6 & 23.9 & 9.7 & 48.6 & 20.4 & 29.7 & 68.4 & 16.2 & 15.3 \\
\hline & SMIP004 & 81.7 & 7.9 & 9.8 & 72.3 & 19.1 & 7.1 & 75.7 & 14.1 & 8.0 & 58.5 & 14.3 & 25.7 & 68.6 & 18.2 & 13.2 \\
\hline \multirow[t]{3}{*}{$48 \mathrm{~h}$} & DMSO & 70.4 & 17.8 & 10.0 & 66.4 & 22.3 & 7.5 & 50.7 & 29.8 & 17.7 & 46.3 & 20.8 & 31.2 & 77.0 & 12.8 & 10.3 \\
\hline & SMIP001 & 83.6 & 8.5 & 6.6 & 86.8 & 6.9 & 3.5 & 71.1 & 13.4 & 13.6 & 57.5 & 13.6 & 27.8 & 77.0 & 8.9 & 14.1 \\
\hline & SMIP004 & 87.3 & 3.5 & 6.6 & 75.8 & 14.7 & 6.4 & 79.7 & 9.0 & 10.4 & 65.8 & 8.5 & 24.3 & 77.6 & 11.5 & 10.9 \\
\hline
\end{tabular}

The data is representative of two independent experiments. 


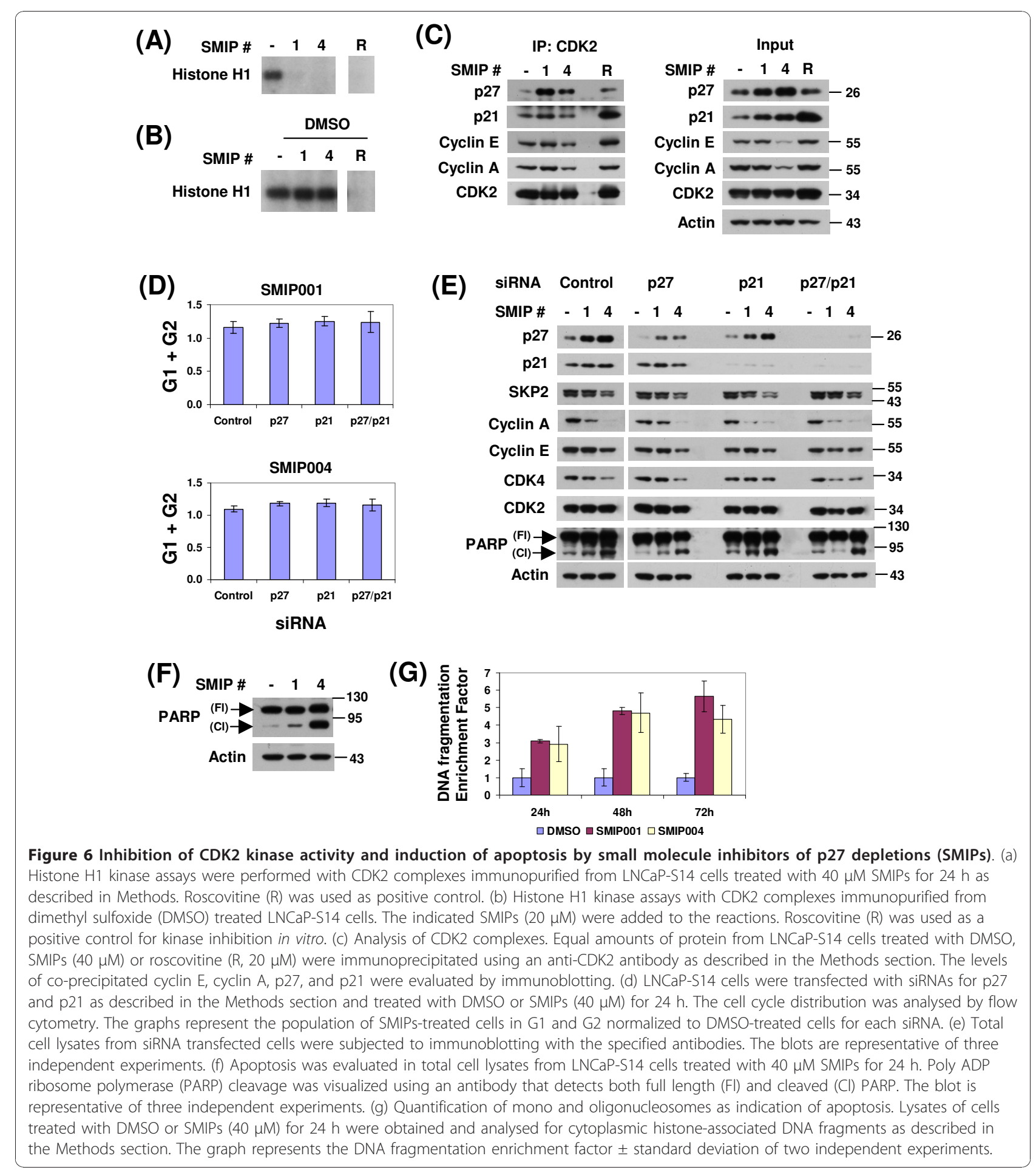

cytoplasmic histone-associated DNA fragments. Cells treated with $40 \mu \mathrm{M}$ SMIP001 and 004 from 24 to $72 \mathrm{~h}$ showed a three- to fivefold increase in the amount of mono and oligonucleosomes, thus confirming the apoptosis-inducing activity of SMIPs.
Effects of SMIPs in other prostate cancer cell lines As shown in Table 2, SMIPs also induced robust G1 delay in parental LNCaP cells as well as in two other prostate cancer cell lines, DU145 and PC3. No such effect was seen with HeLa cells or IMR90 fibroblasts. In 
Table 3 Quantification of p27 and p21 protein levels in protein prostate cancer cell lines, HeLa and IMR90 cells treated with $40 \mu \mathrm{M}$ small molecule inhibitors of p27 depletion (SMIPs) for $\mathbf{2 4} \mathrm{h}$

\begin{tabular}{|c|c|c|c|c|c|c|c|c|c|c|c|c|}
\hline \multirow[b]{2}{*}{ SMIP } & \multicolumn{2}{|l|}{ LNCaP-S14 } & \multicolumn{2}{|l|}{ LNCaP } & \multicolumn{2}{|l|}{ PC3 } & \multicolumn{2}{|l|}{ DU145 } & \multirow{2}{*}{$\begin{array}{c}\text { HeLa } \\
\text { p27 }\end{array}$} & \multicolumn{3}{|c|}{ IMR90 } \\
\hline & p27 & p21 & p27 & p21 & p27 & p21 & p27 & p21 & & p21 & p27 & p21 \\
\hline DMSO & $1.0 \pm 0.0$ & $1.0 \pm 0.0$ & $1.0 \pm 0.0$ & $1.0 \pm 0.0$ & $1.0 \pm 0.0$ & $1.0 \pm 0.0$ & $1.0 \pm 0.0$ & $1.0 \pm 0.0$ & $1.0 \pm 0.0$ & $1.0 \pm 0.0$ & $1.0 \pm 0.0$ & $1.0 \pm 0.0$ \\
\hline SMIP001 & $1.9 \pm 0.5$ & $2.0 \pm 0.6$ & $1.5 \pm 0.7$ & $1.7 \pm 0.6$ & $1.3 \pm 0.6$ & $1.1 \pm 0.5$ & $1.1 \pm 0.2$ & $1.1 \pm 0.3$ & $1.1 \pm 0.1$ & $1.1 \pm 0.2$ & $1.0 \pm 0.0$ & $1.1 \pm 0.0$ \\
\hline SMIP004 & $2.4 \pm 0.7$ & $2.8 \pm 0.7$ & $2.1 \pm 1.1$ & $2.7 \pm 0.1$ & $1.1 \pm 0.3$ & $1.7 \pm 0.9$ & $1.3 \pm 0.1$ & $1.7 \pm 0.5$ & $1.1 \pm 0.2$ & $1.1 \pm 0.1$ & $1.2 \pm 0.3$ & $1.1 \pm 0.0$ \\
\hline MG132 & 1.5 & & $1.9 \pm 0.1$ & 2.9 & $2.0 \pm 1.0$ & $4.1 \pm 0.4$ & $2.4 \pm 0.1$ & 3.1 & $2.2 \pm 0.9$ & $5.9 \pm 1.7$ & $0.9 \pm 0.5$ & $1.1 \pm 0.1$ \\
\hline Bortezomib & 1.8 & & 2.1 & & $2.5 \pm 1.0$ & $4.7 \pm 1.4$ & $1.7 \pm 0.5$ & $2.5 \pm 0.4$ & $1.3 \pm 0.2$ & $2.2 \pm 0.8$ & $1.8 \pm 0.0$ & $1.8 \pm 0.4$ \\
\hline
\end{tabular}

The data is representative of at least four independent immunoblotting experiments.

parental LNCaP cells, G1 delay correlated with an increase in the levels of p27 and p21 as well as a downregulation of cyclins $\mathrm{A}$ and $\mathrm{E}$ and $\mathrm{CDK} 4$, which was particularly prominent with SMIP004 (Table 3 and Figure 7a). Unlike in SKP2 overexpressing LNCaP-S14 cells, SKP2 was downregulated by both SMIP001 and 004 in parental LNCaP cells, although the suppression was substantially greater with SMIP004 than 001 (Figure 7a).
Less pronounced effects on SKP2 were also observed in PC3 and DU145 cells and in IMR90 fibroblasts. In contrast, when averaged over four independent experiments, SMIPs had no consistent effect on p27 levels in PC3 and DU145 cells, although a minor increase in p21 levels was observed (Table 3 ) that coincided with a modest reduction in the levels of cyclin A and CDK4 (Figure 7a). None of the latter effects were apparent either in

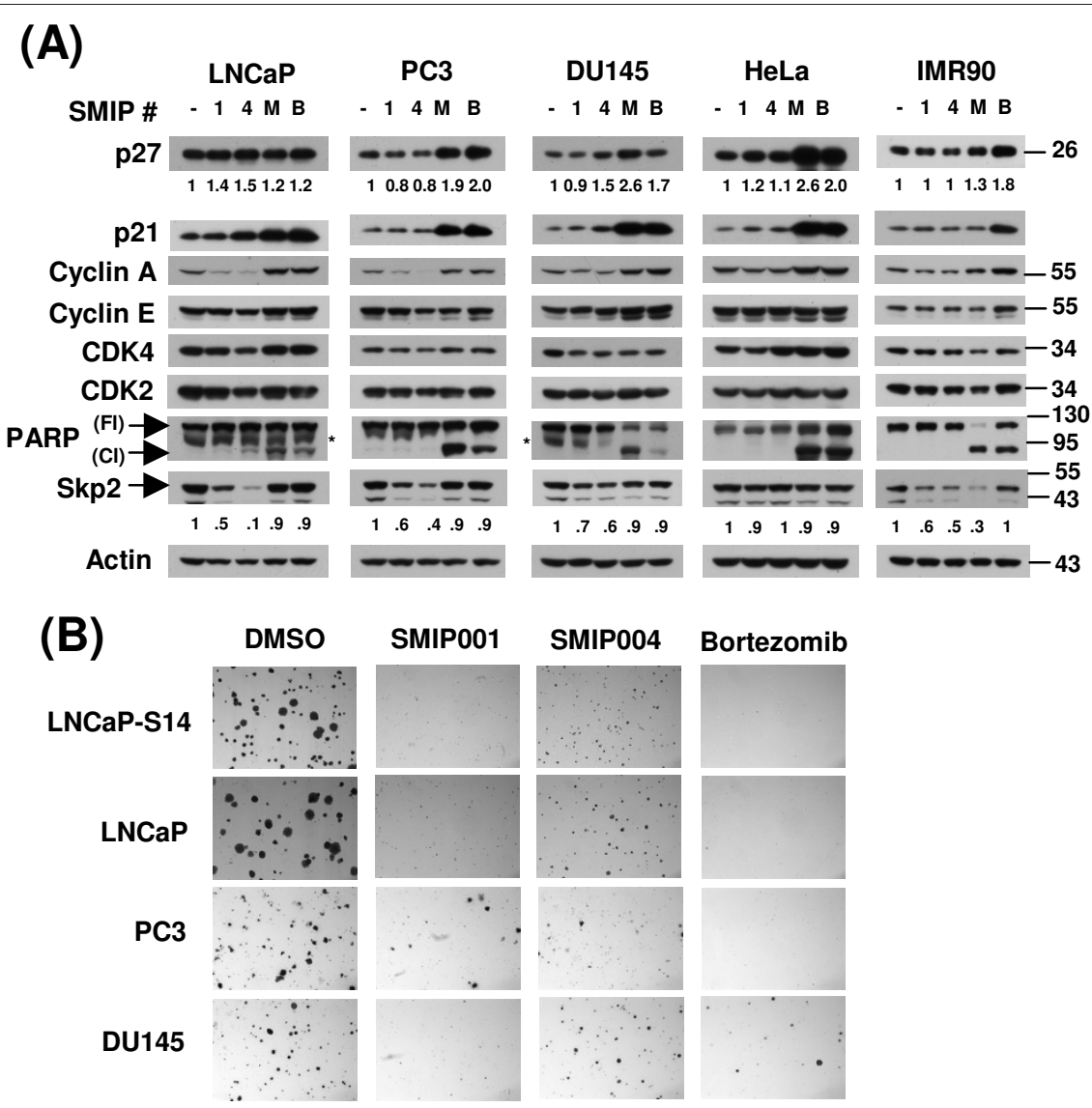

Figure 7 Effects of small molecule inhibitors of p27 depletion (SMIPs) in prostate cancer cell lines. (a) Prostate cancer cell lines, LNCaP, PC3 and DU145 as well as HeLa and IMR90 cells were treated with vehicle (dimethyl sulfoxide; DMSO), SMIPs (40 $\mu$ M) or the proteasome inhibitors, MG132 (M, $20 \mu \mathrm{M})$ and bortezomib (B, $100 \mathrm{nM})$ for $24 \mathrm{~h}$. The levels of the indicated proteins were evaluated by immunoblotting. Asterisks denote an unspecific band. (b) The indicated cell lines were grown in soft agar and treated with vehicle (DMSO), SMIPs (40 $\mu$ M), or bortezomib $(100 \mathrm{nM})$ with addition of fresh compounds in three-day intervals as described in the Methods section. The images are representative of two independent experiments. 
Table 4 Cytotoxicity was assessed by MTT assay in prostate cancer cell lines and normal fibroblasts treated with increasing concentrations $(0.01-80 \mu \mathrm{M})$ of the respective small molecule inhibitors of p27 depletion (SMIPs) for $72 \mathrm{~h}$ and $96 \mathrm{~h}$

\begin{tabular}{lcccc}
\hline & \multicolumn{2}{c}{ SMIP001 } & \multicolumn{2}{c}{ SMIP004 } \\
Cell line & $\mathbf{7 2} \mathbf{h}$ & $\mathbf{9 6} \mathbf{h}$ & $\mathbf{7 2} \mathbf{h}$ & $\mathbf{9 6} \mathbf{h}$ \\
\hline LNCaP-WT & 47.1 & 32.7 & 40 & 2.4 \\
PC3 & $\sim 80$ & 80 & $\mathrm{NE}$ & $\mathrm{NE}$ \\
DU145 & $\sim 40$ & 32.5 & $\mathrm{NE}$ & $\mathrm{NE}$ \\
IMR90 & $40-80$ & $40-80$ & $\mathrm{NE}$ & $\mathrm{NE}$ \\
\hline
\end{tabular}

NE: No effect.

The data in the table represents the IC50 $(\mu \mathrm{M})$. NE: No effect.

HeLa or IMR90 cells. Despite a lack of induction of apoptosis (PARP cleavage, Figure 7a) or overt cytotoxicity (Table 4), the SMIP-induced G1 delay of PC3 or DU145 cells resulted in the same robust inhibition of colony formation in soft agar as observed in LNCaP-S14 and parental LNCaP cells (Figure 7b).

\section{Discussion}

The intimate link between p27 depletion and cancers deriving from the prostate and many other tissues renders pathways controlling p27 abundance attractive targets for the development of novel cancer therapeutics [48]. At the same time, the complexity and apparent redundancy of p27 regulatory pathways raises doubts as to whether targeting a single enzyme or proximal regulator can lead to sustained p27 accumulation in tumour cells. Rather than screening for inhibitors of $\mathrm{SCF}^{\mathrm{SKP} 2}$ or other enzymes controlling p27, we have developed a cell-based phenotypic screening system to identify compounds that can modulate the p27 regulatory network in cancer cells such that normal nuclear p27 levels are restored. The platform was validated in a pilot screen that identified two compounds of previously unknown biological activity that efficiently reversed the depletion of p27 in prostate cancer cells at low micromolar levels. One of these compounds, SMIP004, increased p27 levels by prolonging the half-life of the p27 protein. Therefore, p27 depletion can be reversed by small molecules in cancer cells overexpressing SKP2.

Whereas the cell-based format readily revealed compounds that robustly modulated the screening endpoint - nuclear p27 levels - in intact cells, our pilot screen also exposed the disadvantages of this approach, namely that the molecular targets of SMIPs remain unknown and that the modulated screening endpoint is not necessarily causal to the ultimate cellular effects of the compounds identified. For example, our RNA interference studies showed that neither p27 nor p21 were required for SMIP-induced G1 delay in LNCaP-S14 cells. It is unlikely that inefficiency of the small interfering RNA (siRNA)-mediated knockdown obscured such a requirement for SMIP action, since depletion of p21 and p27 decreased the fraction of cells in G1 thus indicating that the knockdown efficiencies achieved here were functionally consequential. In addition, p21 and p27 levels in SMIP-treated knockdown cells were still lower than or equal to the levels in untreated control cells, suggesting that the minor accumulation of the CKIs observed upon SMIP administration to knockdown cells will be insufficient to cause a cell cycle arrest.

Two potential explanations can be offered to rationalize the dispensability of p21 and p27 for SMIP-induced G1 delay induced by SMIPs: First, it has been well established that mouse embryonic fibroblasts lacking p27 and p21 remain proficient in responding to negative proliferation signals with cell cycle arrest because the pocket proteins p107 and p130, which have CKI activity themselves, compensate for the loss of the p27/p21 $[49,50]$. Secondly, SMIPs induced downregulation of various positive cell cycle regulators, including cyclins $\mathrm{E}$ and $\mathrm{A}$ and CDK4, which was fully maintained upon p27 and p21 knockdown. Thus, it is conceivable that the combined effect of cyclin/CDK downregulation and CDK inhibition by pocket proteins and other CKIs accounts for SMIP-mediated cell cycle delay in the absence of p27 and p21.

Although it appears that the compounds identified in the present pilot screen caused p27 upregulation as a secondary consequence of cell cycle delay, using nuclear p27 accumulation as a screening endpoint readily enabled the identification of cell permeable compounds with antiproliferative activity. Notably, both SMIPs show cancer cell selectivity as they induce cell cycle delay and/or apoptosis in four different prostate cancer cells but not in normal human fibroblasts. Moreover, they inhibit colony formation in soft agar, which is a hallmark of the transformed phenotype of cancer cells and considered a stringent surrogate for in vivo tumour formation [51,52]. Finally, when applied to a more diverse set of compounds with refined drug-like structures, our screening platform may lead to the identification of more potent and direct modulators of nuclear p27 accumulation, similar in characteristics to the recently identified proteasome inhibitor argyrin A, which induces cell cycle arrest and/or apoptosis that is strictly dependent on p27 [45].

The high content screening platform described here also enables chemical genetics strategies for the identification of novel cellular pathways and targets impinging on p27 - for example, the observation that SMIP004 strongly downregulates SKP2 appears significant with regards to its mechanism of action. In a previous work we demonstrated that SKP2 is a rate-limiting component for p27 degradation in LNCaP cells [33]. A recent 
study in mice revealed that inactivation of SKP2 induces tumour cell senescence that is dependent upon p27, p21 and the transcription factor ATF4 [53], which is an integral component of the unfolded protein response (UPR) that is activated in response to endoplasmic reticulum stress. Although the exact mechanism by which SMIP004 downregulates SKP2 is presently unknown, we have observed a robust activation of UPR signalling by the compound (ERB and DAW, manuscript in preperation). A similar downregulation of SKP2 has been noticed with the proteasome inhibitor bortezomib, which is also an UPR inducer [54]. Mechanism of action studies on SMIP004 are therefore beginning to suggest a link between UPR-mediated downregulation of SKP2 and the accumulation of p27 (and perhaps p21). However, a substantial future effort will be required to decipher the exact molecular targets of the compounds identified here. Once those are revealed, target directed high throughput screening campaigns could be initiated to identify a more diverse set of compounds with improved potency toward p27 and clinical potential.

\section{Conclusions}

The results shown here provide proof-of-principle that the cell-based screen we developed provides an effective means of identifying bioactive molecules with cancer selective antiproliferative activity. The advantage of a cell-based screening format is, however, offset by the limitation that the modulated endpoint is not necessarily causal to the ultimate cellular effects of identified compounds, thus requiring additional pathway deconvolution studies. Nevertheless, this approach can be applied to larger and more diverse sets of compounds with refined drug-like properties, revealing both unknown cellular pathways globally impinging on p27 and novel chemotherapeutic lead agents.

\section{Methods}

\section{Compound libraries}

NINDS, Prestwick Peakdale 1, Mixed Commercials, Antimitotic, and Enamine and Known Bioactive Compounds libraries were obtained from The Institute of Chemistry and Cell Biology (ICCB) at Harvard Medical School (MA, USA). Information about the libraries can be found at http://iccb.med.harvard.edu.

\section{SMIPs and other chemical compounds}

SMIP001 to SMIP018 were purchased from Ryan Scientific (SC, USA). SMIP0019 was purchased from ChemDiv, Inc (CA, USA). Roscovitine was purchased from Enxo Life Sciences (formerly Biomol International; NY, USA), bortezomib from LC Laboratories (MA, USA), cycloheximide (CHX) and camptothecin from Sigma (MO, USA), MG132 and epoxomicin from BostonBiochem (MA,
USA). All drugs were dissolved in DMSO and kept at $-80^{\circ} \mathrm{C}$.

\section{Antibodies}

Anti-p27 antibody (610241, 1:5000 for immunoblotting and 1:1000 for immunofluorescence) was obtained from BD Biosciences (NJ, USA). Anti-SKP2 (32-3300, 1:2000 for immunoblotting.) and anti-ubiquitin (13-1600, 1:2000) was from Zymed Laboratories (CA, USA). AntiSKP2 (sc-7164, 1:500 for immunofluorescence), antiCDK2 (sc-163, 1:1000 for immunoblotting, $2 \mu \mathrm{g} / 500 \mathrm{mg}$ protein for immunoprecipitation) and anti-CDK4 (sc260, dil 1:500) from Santa Cruz Biotechnology, Inc (CA, USA). Antibodies for Cyclin E Ab-2 (clone HE12, dil 1:200) and Cyclin A Ab-6 (clone 6E6, dil 1:100) from Thermo Scientific (CA, USA). Anti-p21 (2947, 1:2000) and anti-PARP (9542, 1:1000) were from Cell Signaling Technology (MA, USA). Anti-Tubulin (T5168, 1:5000) was from Sigma Life Science. Anti-Actin (69100, 1:20000) was from MP Biomedicals, LLC (CA, USA). HRP Donkey anti-mouse IgG (715-035-150, 1:5000) and HRP Donkey anti-rabbit IgG (711-035-152, 1:5000) was obtained from Jackson ImmunoResearch Laboratories (PA, USA).

Creation of the LNCaP-S14 cell line and culture conditions Parental LNCaP cells were stably transfected with a plasmid driving the expression of Myc epitope-tagged SKP2 or empty vector (pcDNA3). Briefly, $5 \times 10^{6}$ cells were transfected with $20 \mu \mathrm{g}$ of each plasmid using Lipofectamine 2000 reagent (Invitrogen, CA, USA) following the manufacturer's protocol. Cells were selected in 600 $\mu \mathrm{g} / \mathrm{mL}$ geneticin (G418) until individual colonies were visible. Colonies were picked, passed to 24 well plates and expanded. The levels of p27 and SKP2 were analysed by immunoblotting as described below. LNCaP-S14 (positive clone for SKP2 overexpression), LNCaP-P10 (vector control cell line), LNCaP (parental cell line), PC3 and DU145 cells were maintained in RPMI supplemented with $10 \%$ fetal bovine serum and $5 \%$ penicillin/streptomycin solution. IMR90 and HeLa cells were maintained in DMEM containing 10\% fetal bovine serum, $5 \%$ penicillin/streptomycin and $4 \mathrm{mM}$ glutamine. Cells were grown as a monolayer in a humidified incubator at $37^{\circ} \mathrm{C}$ and $5 \% \mathrm{CO}_{2}$.

Immunofluorescence assay on cover slips and in 384 well plates

The screen relies on the detection of differences in the levels of endogenous p27 by immunofluorescence. LNCaP-S14 cells were seeded at a density of 100,000 cells onto $15 \mathrm{~mm}$ glass cover slips and allowed to attach for 1 day. Cells were treated with vehicle (DMSO) or positive controls (roscovitine, MG132) for $18 \mathrm{~h}$. After the 
incubation, cells were fixed by the addition of $10 \%$ paraformaldehyde in phosphate buffered saline (PBS; final concentration $4 \%$ ) and incubated for $20 \mathrm{~min}$ at room temperature (RT). Cells were permeabilized by washing $3 \times 5$ min with PBS, $0.1 \%$ Triton X100, followed by blocking in 5\% nonfat dry milk in PBS, 0.1\% Triton X100 for $1 \mathrm{~h}$ at RT. Cells were incubated with $50 \mu \mathrm{l}$ primary antibody (anti-p27, 1:1000 in blocking buffer) for $1 \mathrm{~h}$, followed by one wash with blocking buffer. $50 \mu \mathrm{L}$ of secondary antibody (Alexa Fluor 594 goat anti-mouse, Invitrogen A11005, 1:200 in blocking buffer) was added for $1 \mathrm{~h}$. Cells were washed $3 \times 5$ min in PBS, $0.1 \%$ Triton $\mathrm{X} 100$ and stained with Hoechst dye $(1 \mu \mathrm{g} / \mathrm{mL}$ in PBS) for 2 min. Cells were washed twice in PBS and mounted for imaging with a Nikon Type 120 inverted fluorescent microscope using $60 \times$ magnification. Compounds used as positive controls included MG132, epoxomycin and roscovitine, while DMSO was used as negative control. Cells stained with secondary antibody only were used to assess the non-specific (NS) staining background.

The above protocol was adapted to 384 well plates as follows: $4000 \mathrm{LNCaP}-\mathrm{S} 14$ cells per well were seeded into 384-well plates (black with clear bottom) in $30 \mu \mathrm{L}$ RPMI, 10\% fetal bovine serum (FBS). Nuclear p27 staining was done under the same conditions as above but with reducing the volume of solutions to $20 \mu \mathrm{L} /$ well for $10 \%$ para-formaldehyde in PBS, $30 \mu \mathrm{L} /$ well for blocking and wash solutions and $15 \mu \mathrm{L} /$ well for primary and secondary antibody solutions and Hoechst dye. All liquid handling was done with an eight-channel multidrop liquid dispenser (Wellmate, OH, USA) and a wand aspirator (VP Scientific, CA, USA; VP-186L). After staining, plates were sealed and stored in the dark at $4^{\circ} \mathrm{C}$ until scanning.

\section{Images acquisition and analysis}

Images from 384 well plates were acquired by using the ImageXpress Micro inverted epifluorescent automated microscope (Molecular Devices, CA, USA) at dual wave length to detect Hoechst and p27. The microscope was equipped with the Photometrics CoolSNAP ES digital CCD camera and an automated objective and filter cube changers. Two images per well at a $20 \times$ magnification were obtained at each wave length.

Images were analysed with the MetaXpress cellular imaging analysis software using the cell scoring module. Cells were scored positive for Hoechst, if the integrated pixel intensity was 210-fold above local background and positive for p27 when staining was 30 -fold above background (signal obtained with secondary antibody). MetaXpress processing of the raw images provided quantitative measures of the total cell number and the number of p27 positive cells in a given field. The data from both images of each well were combined to get a single number of positive cells. The percentage of positive cells was calculated relative to the total number of cells. Background correction was done by subtracting the number of p27 positive cells in wells stained with secondary antibody only.

The staining protocol was also evaluated using another imaging and software package, the Cell Lab IC100 and Cytoshop software (Beckman Coulter, CA, USA). Minor changes were introduced to the protocol: The cell number was reduced to $3000 /$ well and the secondary Alexa Fluor 568 goat anti mouse antibody was diluted 1:500 in blocking buffer. Four images per well were taken using $10 \times$ magnification with a numerical aperture of 0.25 and a camera binning of $2 \times 2$. A manual threshold was established by comparison of the total nuclear intensity in the positive control and the total intensity obtained in cells stained with the secondary antibody only (unspecific staining) and/or the vehicle control (DMSO). Processing of the raw images provided quantitative measures of the total cell number and the number of p27 positive cells in a given field.

Z'-factor calculation: This parameter was used to assess the quality of the assay in the HTP optimization (HTP Company, CA, USA) [37]. In three independent experiments, LNCaP-S14 cells were seeded in 384 well plates followed by treatment with 0.3\% DMSO (192 wells, negative control) or $20 \mu \mathrm{M}$ roscovitine (192 wells, positive control) for $18 \mathrm{~h}$. The percentage of p27 positive cells was determined as described above and the Z' factor calculated from 576 replicates (each condition) as follows: $Z^{\prime}=1-\left(3 S D_{+}+3 S D_{-}\right) /\left(\right.$Ave $_{+}-$Ave $\left._{-}\right)$, where $\mathrm{SD}_{+}$ is the standard deviation for the positive control, SD. the standard deviation for the negative control, Ave ${ }_{+}$the average for the positive control and Ave is the average for the negative control [37].

\section{Primary screening}

The cell-based screen was performed at the Institute of Chemistry and Cell Biology, Harvard Medical School, using libraries of uncharacterized compounds (Peakdale 1, Mixed Commercials, Antimitotic and Enamine, total of 4888 compounds) plated in $5 \mathrm{mg} / \mathrm{mL}$ stock solutions in DMSO, the NINDS library (1040 compounds, $10 \mathrm{mM}$ in DMSO), the Prestwick Library (960 compounds, $2 \mathrm{mg} / \mathrm{mL}$ ) and a library of 489 known bioactive compounds (plated at $5 \mathrm{mg} / \mathrm{mL}, 1.1 \mathrm{mg} / \mathrm{mL}$, and $0.25 \mathrm{mg} /$ $\mathrm{mL}$ in DMSO) for a total of 7638 compounds. LNCaPS14 cells were seeded onto 384 well plates as described above. Compound stocks (100 nL) were pin-transferred using a robot-controlled stainless-steel pin array, resulting in a 300 -fold-dilution ( 5 to $35 \mu \mathrm{M}$ final screening concentration, depending on individual compound molecular weight) followed by incubation for $18 \mathrm{~h}$. All compound plates were screened in duplicates. Each 
individual plate contained at least eight positive controls (roscovitine, $20 \mu \mathrm{M}$ ), eight negative controls (DMSO, $0.3 \%$ ) and eight wells of cells treated with $0.3 \%$ DMSO and stained only with secondary antibody (non-specific staining). Staining of p27, imaging and analysis was performed as described above. Potential hits were classified according to their $\mathrm{Z}$ score. The $\mathrm{Z}$ score is a simple and widely known normalization method calculated as follows: $\mathrm{Z}=\mathrm{X}_{\mathrm{i}}-\mathrm{X} / \mathrm{S}_{\mathrm{x}}$, where $\mathrm{X}_{\mathrm{i}}$ is the raw measurement on the ith compound, $X$ and $S_{X}$ are the mean and the standard deviation, respectively, of all measurements within each plate [38]. Potential hits were classified as weak if their $Z$ score was between 2 and 3, medium if the $\mathrm{Z}$ score was between 3 and 5 and strong if the $\mathrm{Z}$ score was greater than 5 .

\section{Counter screening}

Target specificity was analysed using LNCaP cells stably expressing the homeobox transcription factor NKX3.1 fused to YFP. In brief, 4000 LNCaP-NKX3.1-YFP (clone $4 \mathrm{~A}$ ) cells were seeded in a 384 well plate and treated with SMIPs for $18 \mathrm{~h}$. Proteasome inhibitors were used as positive controls. Images from 384 well plates were taken using the Cell Lab IC100 automated microscope (Beckman Coulter), and the percentage of cells positive for NKX3.1-YFP was quantified using Cytoshop software (Beckman Coulter). The percentage of NKX3.1-YFP positive cells was determined relative to DMSO treated cells.

Cell specificity was evaluated using HeLa cells stably transfected with a p27-luciferase (p27Luc) construct [43]. Briefly, HeLa-p27Luc cells were seeded in 96 well plates and treated with $40 \mu \mathrm{M}$ of the respective SMIPs or positive controls (proteasome inhibitors). After incubation for $18 \mathrm{~h}$, cells were lysed using Cell Culture Lysis Reagent from Promega (WI, USA) and luciferase activity was determined by the Luciferase Assay System (Promega) using a Veritas microplate luminometer (Turner Biosystems, CA, USA). Protein concentration was measured in a parallel plate using Bio-Rad Protein Assay (Bio-Rad, CA, USA). Luciferase activity was normalized against protein concentration and compared to the activity recovered from DMSO-treated cells.

\section{Immunoblotting}

Total cell lysate from cells treated with vehicle (DMSO) or compounds were obtained by incubating cells in lysis buffer $(25 \mathrm{mM}$ Tris- $\mathrm{HCl} \mathrm{pH} \mathrm{7.4,} 150 \mathrm{mM} \mathrm{NaCl}, 0.5 \%$ Triton $\mathrm{X}-100$, protease inhibitors) for $15 \mathrm{~min}$ at $4^{\circ} \mathrm{C}$. The supernatant was collected by centrifugation and the amount of protein was determined with a Bio-Rad protein assay (BioRad) using BSA as standard. Equal amounts of protein were subjected to SDS-PAGE (4\%-20\% gels, Invitrogen) and transferred to PVDF membranes. The membranes were blocked with TBST (50 mM Tris- $\mathrm{HCl}$ pH 7.5,
$150 \mathrm{mM} \mathrm{NaCl}, 0.05 \%$ Tween-20) containing 5\% non-fat dry milk or bovine serum albumin (BSA) for $1 \mathrm{~h}$ at room temperature, followed by incubation in primary antibodies $4^{\circ} \mathrm{C}$ overnight. Membranes were washed and incubated with secondary antibodies conjugated to HRP (Jackson ImmunoResearch Laboratories) for $1 \mathrm{~h}$ at room temperature. Signals were visualized using the ECL Western Blotting Substrate (Pierce Biotechnology, IL, USA) according to the manufacturer's instructions. Membranes were stripped using Restore $^{\mathrm{TM}}$ Western Blot Stripping Buffer (Pierce Biotechnology). Films were scanned and quantification of the bands was performed using Image J software http://rsbweb.nih.gov/ij/.

\section{Co-immunoprecipitation}

Total lysates of cells treated with vehicle (DMSO), SMIPs or positive controls were prepared by incubation in immunoprecipitation (IP) buffer $(25 \mathrm{mM}$ Tris- $\mathrm{HCl}$, $\mathrm{pH} 7.4 ; 150 \mathrm{mM} \mathrm{NaCl}, 0.5 \%$ Triton $\mathrm{X}-100$, protease inhibitors) for $15 \mathrm{~min}$ at $4^{\circ} \mathrm{C}$. Upon centrifugation, the supernatant was collected and the amount of protein was determined with a Bio-Rad protein assay (Bio-Rad Laboratories) using BSA as standard. Five hundred micrograms of protein was adjusted to $1 \mathrm{~mL}$ with IP buffer and incubated with $10 \mu \mathrm{L}$ anti-CDK2 antibody (sc-163, Santa Cruz Biotech) at $4^{\circ} \mathrm{C}$ for $3 \mathrm{~h}$ with constant rotation, followed by addition of $100 \mu \mathrm{L}$ protein G-sepharose beads (10\% slurry) for $2 \mathrm{~h}$. After four washes for $5 \mathrm{~min}$ each with $1 \mathrm{~mL}$ IP buffer, beads were resuspended in $2 \mathrm{X}$-SDS Laemmli buffer, followed by SDS-PAGE and immunoblotting.

\section{In vitro kinase assay}

Histone $\mathrm{H} 1$ kinase assays were performed as described in reference [55]. Briefly, the total cell lysates from LNCaPS14 cells treated with the respective SMIP $(40 \mu \mathrm{M})$ for 24 $\mathrm{h}$ were prepared in IP lysis buffer supplemented with protease inhibitors followed by IP. Kinase reactions were performed by adding histone $\mathrm{H} 1(1 \mu \mathrm{g})$ and $7.5 \mu \mathrm{Ci}$ $\left[\gamma_{-}{ }^{32} \mathrm{P}\right] \mathrm{ATP}(800 \mathrm{Ci} / \mathrm{mmol}$ Perkin Elmer Life Sciences, MA, USA) in kinase buffer (20 mM $\mathrm{MgCl}_{2}, 10 \mathrm{mM}$ EGTA, $40 \mathrm{mM}$ Hepes, $\mathrm{pH} 7$ ). After incubation at $30^{\circ} \mathrm{C}$ for $20 \mathrm{~min}$, the reaction was stopped by adding $20 \mu \mathrm{L} 2 \times$ SDS gel loading buffer. Samples were separated by electrophoresis, gels were stained and dried, followed by exposure to X-ray film. DMSO was used as negative control and roscovitine (CDK2 inhibitor) as positive control.

\section{Cytotoxicity assay}

LNCaP-S14 (10,000 cells), PC3, DU145 or IMR90 cells (5000 cells) were seeded in 96-well plates and treated with increasing concentrations of the respective SMIPs for $72 \mathrm{~h}$. Cell viability was assessed using the MTT cell proliferation assay $\left(\mathrm{ATCC}^{\circledR}\right.$, Middlesex, UK) according 
to the manufacturer's protocol. $\mathrm{IC}_{50}$ was calculated using the BioDataFit 1.02 software http://www.changbioscience.com/stat/ec50.html.

\section{Determination of protein half-lives by cycloheximide chase}

LNCaP-S14 cells were treated with SMIPs $(40 \mu \mathrm{M})$ for $18 \mathrm{~h}$ followed by the addition of $100 \mu \mathrm{g} / \mathrm{mL}$ cycloheximide $(\mathrm{CHX})$. Cell extracts were obtained as described above at different times after $\mathrm{CHX}$ addition. Protein lysate was subjected to SDS-PAGE and immunoblotting for p27, p21 and SKP2. Tubulin was used as loading control. Protein half-lives were calculated using a web based calculator http://www.1728.com/halflife.htm.

\section{RNA isolation and quantitative polymerase chain reaction} (q-PCR)

Total RNA was isolated from LNCaP-S14 cells treated with $40 \mu \mathrm{M}$ SMIPs or vehicle $(18 \mathrm{~h})$ using the RNeasy Mini Kit (Quiagen, CA, USA), followed by first-strand cDNA synthesis using Omniscript ${ }^{\circledR}$ Reverse Transcription (Quiagen). Real-time PCR analysis was performed on the Stratagene Mx3000p detection system (Stratagene, Agilent, CA, USA) using the SYBR Green PCR Master Mix (ABI, CA, USA) at the Microarray and qPCR Facility of the Sanford-Burnham Medical Research Institute. The primers used were:

5'-ACTGCAGAGACATGGAAGAG-3' and 5'ATGCGTGTCCTCAGAGTTAG-3' for p27 (to amplify a region from nucleotides 608 to 852); 5'-CGATGGAACTTCGACTTTG-3' and 5'-GGGTACAAGACAGTGACAGG-3' for p21 (to amplify a region from nucleotides 142 to 355); and 5'-TGAGCTGCTAAAGGTCTCTG-3' and 5'-ATGTGCTGTACACGAAAAGG-3' for SKP2 (to amplify a region spanning from nucleotide 527 in exon No. 2 to 739 in exon No.4). Briefly, reactions were done in a $25 \mu \mathrm{L}$ reaction volume of q-PCR mixture containing $2 \mu \mathrm{L}$ of cDNA (40 ng) and $250 \mathrm{nM}$ of each primer. Activation of the enzyme was done at $95^{\circ} \mathrm{C}$ for $10 \mathrm{~min}$ followed by 40 cycles of amplification at $95^{\circ} \mathrm{C}$ for $30 \mathrm{~s}, 56^{\circ} \mathrm{C}$ for $1 \mathrm{~min}$ and $72^{\circ} \mathrm{C}$ for $30 \mathrm{~s}$. All reactions were done in duplicates and normalized using GAPDH as control. Primers were design using Primer 3 http://frodo.wi.mit.edu/ primer3/ and synthesized by Valuegene, Inc, CA, USA.

\section{Cell cycle analysis}

Cells were exposed to SMIPs $(40 \mu \mathrm{M})$ for $24 \mathrm{~h}$ and $48 \mathrm{~h}$. Cells were trypsinized, washed with PBS and suspended in $600 \mu \mathrm{L}$ PBS. Cells were fixed by adding $1.4 \mathrm{~mL}$ cold absolute ethanol and kept at $-20^{\circ} \mathrm{C}$ for at least $12 \mathrm{~h}$. After washing once with $\mathrm{PBS}$, the cells were resuspended in $250 \mu \mathrm{L}$ PBS containing $2.5 \mu \mathrm{g}$ RNAse A and incubated for $45 \mathrm{~min}$ at room temperature. Staining was done by adding $40 \mu \mathrm{g} / \mathrm{mL}$ of propidium iodine followed by incubation for $15 \mathrm{~min}$ at room temperature. DNAbound fluorescence was read at 564 to $606 \mathrm{~nm}$ using FACSort and FACSCanto flow cytometers (BD Biosciences) at the Flow Cytometry Facility of the SanfordBurnham Medical Research Institute. Distribution of cells in the different cell cycle phase was determined with ModFit LT 3.2.1 or FlowJo 8.6 software. Aggregates were excluded from the analysis manually using pulse shape or identified by automated modelling in ModFit LT.

\section{Apoptosis assay}

Apoptosis was measured using the Cell Death Detection ELISA (Roche, Basel, Switzerland) following the manufacturer's instructions. Briefly, LNCaP-S14 cells $(0.1 \times$ $10^{6}$ ) were seeded in 12 -well plates and treated with SMIPs $(40 \mu \mathrm{M})$ for $24 \mathrm{~h}$. Cells were collected in medium, spun at $1000 \mathrm{rpm}$, and resuspended in $1 \mathrm{~mL}$ PBS at the specified time points (day 1 to day 3 ). The cell suspension was divided into two parts. The first half was used for determination of cytoplasmic histone-associated DNA fragments (ELISA), the second for protein determination to normalize the ELISA data to the amount of input protein.

\section{siRNA transfection}

LNCaP-S14 cells were seeded in $6 \mathrm{~cm}$ dishes or six-wellplates coated with poly-lysine the day before transfection. 10-20 nM of siRNA was transfected using DharmaFECT 3 (Thermo Scientific) according to the manufacturer's instructions. Briefly, siRNAs were dissolved in siRNA suspension buffer (Quiagen) at $20 \mu \mathrm{M}$, heated to $90^{\circ} \mathrm{C}$ for $1 \mathrm{~min}$ and incubated at $37^{\circ} \mathrm{C}$ for $1 \mathrm{~h}$. siRNAs were added to the DharmaFECT 3 reagent diluted in Optimem media (1:100) and incubated for $20 \mathrm{~min}$ at room temperature. The mix was added to the cells for $24 \mathrm{~h}$. Treatment with SMIPs $(40 \mu \mathrm{M})$ or vehicle was carried on for another $24 \mathrm{~h}$. Cells were obtained for FACS or lysed for immunoblotting analysis as described above. Untransfected cells as well as cells transfected with non-specific siRNA were used as controls. Silencer $^{\circledR}$ Negative Control siRNA No.1 from Ambion (Applied Biosciences, CA, USA) was used as non-specific control siRNA. siRNA target sequences for p27 and p21 synthesized by IDT (Integrated DNA Technologies Inc, Iowa, USA) were as follows; p27 siRNA: AAGGUUGCAUACUGAGCCAAG, and p21 siRNA: AACAUACUGGCCUGGACUGUU [56].

\section{Soft agar assay}

Agar Noble (Difco, MD, USA) was suspended at $6 \%$ in water and autoclaved. A dilution 1:10 was made with RPMI culture medium and added to six-well plates (2 mL). We suspended 20,000 cells were in $0.5 \mathrm{~mL}$ 
RPMI culture medium (containing drugs), added to $0.5 \mathrm{~mL}$ of agar $(0.6 \%)$ and poured immediately into a six-well plate containing hardened bottom agar. Cells were fed with fresh medium containing DMSO, SMIP001, SMIP004 or bortezomib every third days. Images were taken after 14 days using a Nikon Eclipse E600 Microscope.

\section{Additional material}

Additional file 1: Supplementary Table 1. The table shows 176 small molecule inhibitors of p27 depletion (SMIPs) identified in the primary screening. Compounds were classified according to their $Z$ factors as strong (S), medium (M) or weak (W). Their position in the screening (stock plate and well), simplified molecular input line entry specification (SMILES), name and vendor are also listed. A column with known biological actions is also shown for some compounds.

Additional file 2: Supplementary Table 2: The table shows the cell cycle distribution of LNCaP-S14 transfected with small interfering RNA for p27 and p21 and treated with SMIP004 (40 $\mu \mathrm{M})$ as described in the Methods section. Cell were analysed by flow cytometry and the percentage of cells in the different phases of the cell cycle were calculated.

\section{Abbreviations}

ADT: androgen deprivation therapy; CDK: cyclin-dependent kinase; CHX: cycloheximide; DMSO: dimethyl sulfoxide; IB: immunoblotting; IP: immunoprecipitation; PCa: prostate cancer; q-PCR: quantitative polymerase chain reaction; siRNA: small interfering RNA; SMILES: simplified molecular input line entry specification; SMIP: small molecule inhibitors of p27 depletion; UPR: unfolded protein response; UPS: ubiquitin proteasome system; YFP: yellow fluorescent protein.

\section{Acknowledgements}

The authors would like to acknowledge the support of staff members of the ICCB at Harvard Medical School (Sean M Johnston and David Wrobel) and the Conrad Prebys Center for Chemical Genomics at Sanford-Burnham Medical Research Institute (Susanne Heynen-Genel). We are grateful to Alfred $\mathrm{L}$ Goldberg for his assistance with the proteasome activity assays and Dr Bill Kaelin for the HeLa-p27-luc cell line. This work was funded by NIH grants R01CA116571, R21NS061675 and RO1GM59780 to DAW and by the Department of the Army, Grant 00475063, Prostate Cancer Training Award to ERB. The generous support of Jeanne and Gary Herberger for this work is gratefully acknowledged.

\section{Author details}

Signal Transduction Program, Sanford-Burnham Medical Research Institute, La Jolla, CA 92037, USA. GE Healthcare, Life Sciences, Shanghai 201203, China. ${ }^{3}$ Sanford-Burnham Medical Research Institute at Lake Nona, Orlando, FL 32827, USA.

\section{Authors' contributions}

The vast majority of the experiments in this study were carried out by the principal author, ERB. She developed the screening assay, performed all screening and counter screening, carried out the bulk of the validation assays and drafted the manuscript. CCY generated the LNCaP-NKX3.1-YFP cell line used for counter screening and assisted with advice. $L L$ generated and characterized the LNCaP-S14 cell line used for screening. GPR assisted with advice in prioritizing SMIPs for follow-up based in their chemical features and directed the HPLC analysis of SMIPS. DAW developed the concept for this work, participated in study design, secured funding, assisted with kinase assays and edited the manuscript.

Received: 18 November 2010 Accepted: 23 December 2010 Published: 23 December 2010
References

1. Chu IM, Hengst L, Slingerland JM: The Cdk inhibitor p27 in human cancer: prognostic potential and relevance to anticancer therapy. Nat Rev Cancer 2008, 8:253-267.

2. De Marzo AM, Meeker AK, Epstein Jl, Coffey DS: Prostate stem cell compartments: expression of the cell cycle inhibitor p27Kip1 in normal, hyperplastic, and neoplastic cells. Am J Pathol 1998, 153:911-919.

3. Cheville JC, Lloyd RV, Sebo TJ, Cheng L, Erickson L, Bostwick DG, Lohse CM, Wollan P: Expression of p27kip1 in prostatic adenocarcinoma. Mod Pathol 1998, 11:324-328.

4. Cote RJ, Shi Y, Groshen S, Feng AC, Cordon-Cardo C, Skinner D, Lieskovosky G: Association of p27Kip1 levels with recurrence and survival in patients with stage C prostate carcinoma. J Natl Cancer Inst 1998, 90:916-920.

5. Kokontis JM, Hay N, Liao S: Progression of LNCaP prostate tumor cells during androgen deprivation: hormone-independent growth, repression of proliferation by androgen, and role for p27Kip 1 in androgen-induced cell cycle arrest. Mol Endocrinol 1998, 12:941-953.

6. Chen J, Willingham T, Shuford M, Nisen PD: Tumor Suppression and Inhibition of Aneuploid Cell Accumulation in Human Brain Tumor Cells by Ectopic Overexpression of the Cyclin-dependent Kinase Inhibitor p27KIP1. J Clin Invest 1996, 97:1983-1988.

7. Craig C, Wersto R, Kim M, Ohri E, Li Z, Katayose D, Lee SJ, Trepel J, Cowan K, Seth P: A recombinant adenovirus expressing p27Kip1 induces cell cycle arrest and loss of cyclin-Cdk activity in human breast cancer cells. Oncogene 1997, 14:2283-2289.

8. Hengst L, Reed SI: Translational control of p27Kip1 accumulation during the cell cycle. Science 1996, 271:1861-1864.

9. Cheng M, SexI V, Sherr CJ, Roussel MF: Assembly of cyclin D-dependent kinase and titration of $\mathrm{p} 27 \mathrm{Kip} 1$ regulated by mitogen-activated protein kinase kinase (MEK1). Proc Natl Acad Sci USA 1998, 95:1091-1096.

10. Viglietto G, Motti ML, Bruni P, Melillo RM, D'Alessio A, Califano D, Vinci F, Chiappetta G, Tsichlis P, Bellacosa A, Fusco A, Santoro M: Cytoplasmic relocalization and inhibition of the cyclin-dependent kinase inhibitor p27(Kip1) by PKB/Akt-mediated phosphorylation in breast cancer. Nat Med 2002, 8:1136-1144.

11. Chu I, Sun J, Arnaout A, Kahn H, Hanna W, Narod S, Sun P, Tan CK, Hengst L, Slingerland J: p27 phosphorylation by Src regulates inhibition of cyclin E-Cdk2. Cell 2007, 128:281-294.

12. Grimmler M, Wang $Y$, Mund $T$, Cilensek $Z$, Keidel EM, Waddell MB, Jakel H, Kullmann M, Kriwacki RW, Hengst L: Cdk-inhibitory activity and stability of p27Kip1 are directly regulated by oncogenic tyrosine kinases. Cell 2007, 128:269-280.

13. Tsvetkov LM, Yeh KH, Lee SJ, Sun H, Zhang H: p27(Kip1) ubiquitination and degradation is regulated by the SCF(Skp2) complex through phosphorylated Thr187 in p27. Curr Biol 1999, 9:661-664.

14. Alessandrini A, Chiaur DS, Pagano M: Regulation of the cyclin-dependent kinase inhibitor p27 by degradation and phosphorylation. Leukemia 1997, 11:342-345.

15. Kawamata N, Morosetti R, Miller CW, Park D, Spirin KS, Nakamaki T, Takeuchi S, Hatta Y, Simpson J, Wilcyznski S, et al: Molecular analysis of the cyclin-dependent kinase inhibitor gene p27/Kip1 in human malignancies. Cancer Res 1995, 55:2266-2269.

16. Ponce-Castaneda MV, Lee MH, Latres E, Polyak K, Lacombe L, Montgomery K, Mathew S, Krauter K, Sheinfeld J, Massague J, et al: p27Kip1: chromosomal mapping to 12p12-12p13.1 and absence of mutations in human tumors. Cancer Res 1995, 55:1211-1214.

17. Pietenpol JA, Bohlander SK, Sato Y, Papadopoulos N, Liu B, Friedman C, Trask BJ, Roberts JM, Kinzler KW, Rowley JD, et al: Assignment of the human p27Kip1 gene to 12 p13 and its analysis in leukemias. Cancer Res 1995, 55:1206-1210.

18. Cordon-Cardo C, Koff A, Drobnjak M, Capodieci P, Osman I, Millard SS, Gaudin PB, Fazzari M, Zhang ZF, Massague J, Scher HI: Distinct altered patterns of p27KIP1 gene expression in benign prostatic hyperplasia and prostatic carcinoma. J Natl Cancer Inst 1998, 90:1284-1291.

19. Catzavelos C, Bhattacharya N, Ung YC, Wilson JA, Roncari L, Sandhu C, Shaw P, Yeger H, Morava-Protzner I, Kapusta L, Franssen E, Pritchard Kl, Slingerland JM: Decreased levels of the cell-cycle inhibitor p27Kip1 protein: prognostic implications in primary breast cancer. Nat Med 1997, 3:227-230.

20. Pagano M, Tam SW, Theodoras AM, Beer-Romero P, Del Sal G, Chau V, Yew PR, Draetta GF, Rolfe M: Role of the ubiquitin-proteasome pathway 
in regulating abundance of the cyclin-dependent kinase inhibitor p27. Science 1995, 269:682-685.

21. Hershko A, Ciechanover A: The ubiquitin system. Annu Rev Biochem 1998, 67:425-479.

22. Carrano AC, Eytan E, Hershko A, Pagano M: Skp2 is required for ubiquitinmediated degradation of the CDK inhibitor p27. Nature Cell Biol 1999, 1:193-199.

23. Hara T, Kamura T, Kotoshiba S, Takahashi H, Fujiwara K, Onoyama I, Shirakawa M, Mizushima N, Nakayama Kl: Role of the UBL-UBA Protein KPC2 in Degradation of p27 at G1 Phase of the Cell Cycle. Mol Cell Biol 2005, 25:9292-9303.

24. Hattori T, Isobe T, Abe K, Kikuchi H, Kitagawa K, Oda T, Uchida C, Kitagawa M: Pirh2 promotes ubiquitin-dependent degradation of the cyclin-dependent kinase inhibitor p27Kip1. Cancer Res 2007, 67:10789-10795.

25. Kamura T, Hara T, Matsumoto M, Ishida N, Okumura F, Hatakeyama S, Yoshida M, Nakayama K, Nakayama Kl: Cytoplasmic ubiquitin ligase KPC regulates proteolysis of p27(Kip1) at G1 phase. Nat Cell Biol 2004, 6:1229-1235, Epub 2004 Nov 1227.

26. Nakayama K, Nagahama H, Minamishima YA, Miyake S, Ishida N, Hatakeyama S, Kitagawa M, lemura S, Natsume T, Nakayama KI: Skp2mediated degradation of p27 regulates progression into mitosis. Dev Cell 2004, 6:661-672.

27. Gstaiger M, Jordan R, Lim M, Catzavelos C, Mestan J, Slingerland J, Krek W: Skp2 is oncogenic and overexpressed in human cancers. Proc Natl Acad Sci USA 2001, 98:5043-5048.

28. Kudo Y, Kitajima S, Sato S, Miyauchi M, Ogawa I, Takata T: High expression of S-phase kinase-interacting protein 2, human F-box protein, correlates with poor prognosis in oral squamous cell carcinomas. Cancer Res 2001, 61:7044-7047.

29. Yang G, Ayala G, De Marzo A, Tian W, Frolov A, Wheeler TM, Thompson TC, Harper JW: Elevated Skp2 protein expression in human prostate cancer: association with loss of the cyclin-dependent kinase inhibitor p27 and PTEN and with reduced recurrence-free survival. Clin Cancer Res 2002, 8:3419-3426.

30. Hershko D, Bornstein G, Ben-Izhak O, Carrano A, Pagano M, Krausz MM, Hershko A: Inverse relation between levels of p27(Kip1) and of its ubiquitin ligase subunit Skp2 in colorectal carcinomas. Cancer 2001, 91:1745-1751.

31. Slingerland J, Pagano M: Regulation of the cdk inhibitor p27 and its deregulation in cancer. I Cell Physiol 2000, 183:10-17.

32. Shim EH, Johnson L, Noh HL, Kim YJ, Sun H, Zeiss C, Zhang H: Expression of the F-box protein SKP2 induces hyperplasia, dysplasia, and low-grade carcinoma in the mouse prostate. Cancer Res 2003, 63:1583-1588.

33. Lu L, Schulz H, Wolf DA: The F-box protein SKP2 mediates androgen control of p27 stability in LNCaP human prostate cancer cells. BMC Cell Biol 2002, 3:22

34. Sumimoto H, Yamagata S, Shimizu A, Miyoshi H, Mizuguchi H, Hayakawa T, Miyagishi M, Taira K, Kawakami Y: Gene therapy for human small-cell lung carcinoma by inactivation of Skp-2 with virally mediated RNA interference. Gene Ther 2004

35. Cardozo T, Pagano M: Wrenches in the works: drug discovery targeting the SCF ubiquitin ligase and APC/C complexes. BMC Biochem 2007, 8(Suppl 1):S9.

36. Horoszewicz JS, Leong SS, Chu TM, Wajsman ZL, Friedman M, Papsidero L, Kim U, Chai LS, Kakati S, Arya SK, Sandberg AA: The LNCaP cell line-a new model for studies on human prostatic carcinoma. Prog Clin Biol Res 1980, 37:115-132.

37. Zhang JH, Chung TD, Oldenburg KR: A Simple Statistical Parameter for Use in Evaluation and Validation of High Throughput Screening Assays. J Biomol Screen 1999, 4:67-73.

38. Malo N, Hanley JA, Cerquozzi S, Pelletier J, Nadon R: Statistical practice in high-throughput screening data analysis. Nat Biotechnol 2006, 24:167-175.

39. Duijn PWV, Trapman J: PI3K/Akt signaling regulates p27kip1expression via Skp2 in PC3 and DU145 prostate cancer cells, but is not a major factor in p27kip1 regulation in LNCaP and PC346 cells. The Prostate 2006, 66:749-760.

40. Zhang GJ, Kaelin WG Jr: Bioluminescent imaging of ubiquitin ligase activity: measuring Cdk2 activity in vivo through changes in p27 turnover. Methods Enzymol 2005, 399:530-549.
41. Li X, Guan B, Maghami S, Bieberich CJ: NKX3.1 is regulated by protein kinase CK2 in prostate tumor cells. Mol Cell Biol 2006, 26:3008-3017.

42. Guan B, Pungaliya P, Li X, Uquillas C, Mutton LN, Rubin EH, Bieberich CJ: Ubiquitination by TOPORS regulates the prostate tumor suppressor NKX3.1. J Biol Chem 2008, 283:4834-4840.

43. Zhang GJ, Safran M, Wei W, Sorensen E, Lassota P, Zhelev N, Neuberg DS, Shapiro G, Kaelin WG Jr: Bioluminescent imaging of Cdk2 inhibition in vivo. Nat Med 2004, 10:643-648.

44. Majumder PK, Grisanzio C, O'Connell F, Barry M, Brito JM, Xu Q, Guney I, Berger R, Herman P, Bikoff R, Fedele G, Baek WK, Wang S, Ellwood-Yen K, Wu H, Sawyers CL, Signoretti S, Hahn WC, Loda M, Sellers WR: A prostatic intraepithelial neoplasia-dependent p27 Kip1 checkpoint induces senescence and inhibits cell proliferation and cancer progression. Cancer Cell 2008, 14:146-155.

45. Nickeleit I, Zender S, Sasse F, Geffers R, Brandes G, Sorensen I, Steinmetz H, Kubicka S, Carlomagno T, Menche D, Gutgemann I, Buer J, Gossler A, Manns MP, Kalesse M, Frank R, Malek NP: Argyrin a reveals a critical role for the tumor suppressor protein p27(kip1) in mediating antitumor activities in response to proteasome inhibition. Cancer Cell 2008, 14:23-35.

46. Bornstein G, Bloom J, Sitry-Shevah D, Nakayama K, Pagano M, Hershko A: Role of the SCFSkp2 ubiquitin ligase in the degradation of p21Cip1 in S phase. J Biol Chem 2003, 278:25752-25757.

47. Montagnoli A, Fiore F, Eytan E, Carrano AC, Draetta GF, Hershko A, Pagano M: Ubiquitination of p27 is regulated by Cdk-dependent phosphorylation and trimeric complex formation. Genes Dev 1999 13:1181-1189.

48. Nickeleit I, Zender S, Kossatz U, Malek NP: p27kip1: a target for tumor therapies? Cell Div 2007, 2:13.

49. Soeiro I, Mohamedali A, Romanska HM, Lea NC, Child ES, Glassford J, Orr SJ, Roberts C, Naresh KN, Lalani E-N, Mann DJ, Watson RJ, Thomas NSB, Lam EW-F: p27Kip1 and p130 Cooperate To Regulate Hematopoietic Cell Proliferation In Vivo. Mol Cell Biol 2006, 26:6170-6184.

50. Coats S, Whyte P, Fero ML, Lacy S, Chung G, Randel E, Firpo E, Roberts JM: A new pathway for mitogen-dependent $\mathrm{Cdk} 2$ regulation uncovered in p27Kip1-deficient cells. 1999, 9:163-173.

51. Macpherson I, Montagnier L: Agar Suspension Culture for the Selective Assay of Cells Transformed by Polyoma Virus. Virology 1964, 23:291-294.

52. Freedman VH, Shin SI: Cellular tumorigenicity in nude mice: correlation with cell growth in semi-solid medium. Cell 1974, 3:355-359.

53. Lin HK, Chen Z, Wang G, Nardella C, Lee SW, Chan CH, Yang WL, Wang J, Egia A, Nakayama KI, Cordon-Cardo C, Teruya-Feldstein J, Pandolfi PP: Skp2 targeting suppresses tumorigenesis by Arf-p53-independent cellular senescence. Nature 2010, 464:374-379.

54. Uddin S, Ahmed M, Bavi P, El-Sayed R, Al-Sanea N, AbdulJabbar A, Ashari LH, Alhomoud S, Al-Dayel F, Hussain AR, Al-Kuraya KS: Bortezomib (Velcade) induces p27Kip1 expression through S-phase kinase protein 2 degradation in colorectal cancer. Cancer Res 2008, 68:3379-3388.

55. Wolf DA, Hermeking $H$, Albert T, Herzinger T, Kind P, Eick D: A complex between E2F and the pRb-related protein p130 is specifically targeted by the simian virus 40 large $T$ antigen during cell transformation. Oncogene 1995, 10:2067-2078.

56. Liu S, Yamauchi H: p27-Associated G1 arrest induced by hinokitiol in human malignant melanoma cells is mediated via down-regulation of $\mathrm{pRb}$, Skp2 ubiquitin ligase, and impairment of Cdk2 function. Cancer Lett 2009, 286:240-249.

doi:10.1186/1741-7007-8-153

Cite this article as: Rico-Bautista et al:: Chemical genetics approach to restoring p27Kip1 reveals novel compounds with antiproliferative activity in prostate cancer cells. BMC Biology 2010 8:153. 